\title{
Clinically-Relevant ABC Transporter for Anti-Cancer Drug Resistance
}

OPEN ACCESS

Edited by:

Caiyun Fu,

Zhejiang Sci-Tech University, China

Reviewed by:

Guozheng Huang,

Anhui University of Technology, China

Xiao-Feng Xiong,

Sun Yat-Sen University, China

*Correspondence:

Qiu Sun

sunqiu@scu.edu.cn

Lili Tian

fly51114@163.com

${ }^{\dagger}$ These authors have have contributed equally to this work and share first authorship

Specialty section:

This article was submitted to Pharmacology of Anti-Cancer Drugs, a section of the journal Frontiers in Pharmacology

Received: 31 December 2020 Accepted: 16 March 2021

Published: 19 April 2021

Citation:

Xiao $H$, Zheng $Y$, Ma L, Tian $L$ and Sun $Q$ (2021) Clinically-Relevant ABC

Transporter for Anti-Cancer

Drug Resistance.

Front. Pharmacol. 12:648407.

doi: $10.3389 /$ fphar.2021.648407

\author{
Huan Xiao ${ }^{1 \dagger}$, Yongcheng Zheng ${ }^{1 \dagger}$, Lingling $\mathrm{Ma}^{1}$, Lili Tian ${ }^{2 *}$ and Qiu Sun ${ }^{1 *}$ \\ ${ }^{1}$ State Key Laboratory of Biotherapy, Cancer Center, West China Hospital, Sichuan University and Collaborative Innovation \\ Center for Biotherapy, Chengdu, China, ${ }^{2}$ Department of Anesthesiology, Sichuan Provincial People's Hospital, University of \\ Electronic Science and Technology of China, Chengdu, China
}

Multiple drug resistance (MDR), referring to the resistance of cancer cells to a broad spectrum of structurally and mechanistically unrelated drugs across membranes, severely impairs the response to chemotherapy and leads to chemotherapy failure. Overexpression of ATP binding cassette (ABC) transporters is a major contributing factor resulting in MDR, which can recognize and mediate the efflux of diverse drugs from cancer cells, thereby decreasing intracellular drug concentration. Therefore, modulators of $\mathrm{ABC}$ transporter could be used in combination with standard chemotherapeutic anticancer drugs to augment the therapeutic efficacy. This review summarizes the recent advances of important cancer-related $\mathrm{ABC}$ transporters, focusing on their physiological functions, structures, and the development of new compounds as ABC transporter inhibitors.

Keywords: ABCC1, ABCG2, ABCB1, MDR, anti-cancer

\section{INTRODUCTION}

Multidrug resistance (MDR) refers to the resistance of a wide spectrum of structurally and mechanistically unrelated drugs across the membrane. This process is among the culprits of failure of cancer chemotherapy, since the cancer cells can efflux chemotherapy agents and therefore reduce the intracellular drug levels (Ahmed et al., 2020). Members of the ATP-binding cassette family have been found to be involved in this process. To be specific, the ABC transporter family can be divided into seven subfamilies according to their genome sequences and TMDs (transmembrane domain) structures (Taylor et al., 2017). Some of them have been reported to act both as importers and exporters of bacteria, however, in eukaryotic cells, they all efflux pumps (Robey et al., 2018). P-glycoprotein (P-gp) was the first identified member within this family and a high-resolution structure of the mouse homolog, which has $87 \%$ sequence identity with human has been elucidated (Juliano and Ling, 1976). Except for P-gp, ABCC1(also known as MRP1)and ABCG2 (also known as BCRP) have also been extensively studied (Toyoda et al., 2019; Ambjørner et al., 2020), confirming their prominent roles in multidrug resistance of cancer cells. During the past few decades, numerous efforts have been made to solve the drug resistance caused by these transporter proteins. However, most of these attempts lead to disappointing results for both the first generation and the second generation of inhibitors, because they exhibit either unacceptable levels of toxicity or less potential inhibiting effects (Adamska and Falasca, 2018). So far, more inhibitors have been exploited (from nature or synthetic sources Gonçalves et al., 2020). In addition, researchers have achieved a deeper understanding of the phenomenon of chemotherapy resistance through their concerns to the genes and signaling pathways that modulate the expression of these proteins (Li et al., 2018; Sultan et al., 2018; Huang et al., 2020; Zhou et al., 2020). In this review, we summarize the recent progress of the most clinically significant $A B C$ transporters $A B C B 1, A B C G 2$, and $A B C C 1$ that cause multi-drug resistance during cancer therapy, with the emphasis on novel small molecule compounds that are 
tested in preclinical and clinical studies, mainly on natural products, synthetic compounds, aiming to provide a wider perspective to understand the multidrug resistance and new strategies targeting $\mathrm{ABC}$ transporters in cancer treatment.

\section{LOCATIONS, SUBSTRATES, CANCER TYPE}

\section{ABCB1 (P-gp)}

$\mathrm{P}$-gp was the first found human $\mathrm{ABC}$ transporter of all known ones and was identified as a glycoprotein responsible for modulating drug permeability (Juliano and Ling, 1976). MDR, the gene encoding P-gp, is located in chromosome 7 at q21 and contains 28 exons encoding 1280 amino acids of this $170 \mathrm{kDa}$ protein (Gottesman et al., 1995). P-gp are similarly expressed in human and mouse tissues, with a more biased expression in excretory tissues, including breast, blood-brain barrier, liver, pancreas, and kidney, and in the apical membrane of epithelial cells located at physiological barriers (Sita et al., 2017; Wang et al., 2017; Christie et al., 2019; Zhang et al., 2020). P-gp exports neutral or positively charged hydrophobic compounds and xenobiotics from cells, thereby protecting them from cytotoxicity (Sharom, 2011; Fletcher et al., 2016). The critical role of P-gp in the blood-brain barrier (also known as BBB), was first illustrated by Schinkel et al. (Schinkel et al., 1994). They found the deletion of $A b c b 1 a$ and $A b c b 1 b$ can lead to CNS toxicity from ivermectin, however, despite its defensive role in protecting cells, the overexpression of P-gp mRNA and protein in clinical specimens in breast, kidney, and lung cancers portends a poor response to chemotherapy, resulting in low survival rates (Robey et al., 2010; Amiri-Kordestani et al., 2012). P-gp can efflux chemotherapy agents and reduce intracellular drug levels (Ahmed et al., 2020), which is one of the major causes of chemo-resistance. The major substrates involved in the multidrug resistance of $\mathrm{P}$-gp are structurally and mechanistically unrelated drugs (Abdallah et al., 2015; Yu et al., 2016; Bugde et al., 2017; Gameiro et al., 2017; Lu et al., 2017). Moreover, P-gp is preferable to express in poorly differentiated and most invasive cells (Ohtsuki et al., 2007; Mesraoua et al., 2019). In a range of soft tissue sarcomas, P-gp expresses most in the largest and most aggressive tumors (Oda et al., 2005). Single-nucleotide polymorphisms (SNP) occurring in $A B C B 1$ genes can result in increased or decreased transporter efficacy, depending on the gene type of the variants, which remains complex so far (Dulucq et al., 2008; Zu et al., 2014).

\section{ABCG2}

ABCG2 plays a pivotal role in extruding exogenous and endogenous substrates and drugs (Ando et al., 2007; Chen YL et al., 2016; Halwachs et al., 2016; Gewin et al., 2019; Mares et al., 2019; Orlando et al., 2019; Traxl et al., 2019), which is related to many multidrug resistant cancer cell lines, including acute lymphoblastic leukemia (ALL), retinal progenitors, hepatic metastases, gastric carcinoma, fibrosarcoma, nonsmall cell lung cancer, glioblastoma and myeloma (Natarajan et al., 2012; Olarte Carrillo et al., 2017; Abdel Gaber et al., 2018; Reustle et al., 2018;
Zhang et al., 2018). ABCG2 locates in the plasma membrane of the cell and expresses in normal tissues like placenta, prostate, kidney, blood-brain barrier, liver, ovary, small intestine, and seminal vesicle (Jackson et al., 2018), which is responsible for regulating the intracellular levels of hormones, lipids, ion and intracellular organelles such as mitochondrion (Ding et al., 2019), lysosome (Chapuy et al., 2008), endoplasmic reticulum (Kashiwayama et al., 2009), Golgi apparatus (Tsuchida et al., 2008). ABCG2 also has a wide range of mechanistically and structurally different substrates, such as mitoxantrone, methotrexate, camptothecins, topotecan and irinotecan, SN-38, epipodophyllotoxin, imidazoacridinones, the anthracycline doxorubicin (Bram et al., 2009a; Bram et al., 2009b; Mao and Unadkat, 2015) and tyrosine kinase inhibitors (Dohse et al., 2010; Hegedüs et al., 2012). ABCG2 has a less important role in uric acid transport, however, its dysfunction leads to several diseases linked to hyperuricaemia such as gout, kidney disease, and hypertension (Bram et al., 2009b; Ishikawa et al., 2013). What is more, phytoestrogen sulfate conjugates (Wetering and Sapthu, 2012), uremic toxin, and indoxyl sulfate (Takada et al., 2018) are unique substrates of ABCG2. A genetically engineered mouse model about BRCA1-associated breast cancer (Brca1-/-p53-/mice) has identified that ABCG2 overexpression is the cause of acquired topotecan resistance, and the genetic ablation of ABCG2 improves the survival rate of topotecan-treated animals (Zander et al., 2010). In fact, in some cancer cell lines, more than one ABC transporter is overexpressed. High levels of ABCG2, ABCB1, and $\mathrm{ABCC} 1$ have been found within primitive leukemic CD34+/38cells (Raaijmakers et al., 2005). The co-expression contributes to multidrug resistance, which requires multi-transporter inhibitors to achieve a better clinical outcome (Robey et al., 2010). However, although the ABCG2-involved multidrug resistance mechanisms are basically clear, the clinical trial relevant to ABCG2 inhibitors has received few satisfying results (Fletcher et al., 2016).

\section{ABCC1}

ABCC1 was identified in 1992 from human small-cell lung cancer cell lines whose drug resistant behavior occurred without the overexpression of P-gp (Cole et al., 1992). ABCC1 expresses in the plasma membrane of some normal tissues and cells including liver, kidney, lung, intestine, blood-brain barrier and peripheral blood monocellular cells (Uhlén et al., 2015). Overexpression of $\mathrm{ABCC} 1$ is related to endometria, acute myeloblastic, glioma, lymphoblastic leukemia, head and neck, non-small cell lung cancer, neuroblastoma, melanoma, prostate, breast, renal, thyroid cancer (Cole, 2014; Johnson and Chen, 2017; Emmanouilidi et al., 2020; Si et al., 2020). To be specific, ABCC1 is a lipophilic anion pump, conferring resistance to anti-cancer drugs (Cole, 2014). Compared with P-gp, the substrates of $\mathrm{ABCC} 1$ have more diverse structures and most of them are amphipathic organic acids with large hydrophobic groups (Kumar and Jaitak, 2019). Endogenous substrates are mainly pro-inflammatory molecules such as Leukotrienes C4 (LTC4), hormones such as estrogens and prostaglandins, sphingosine-1-phosphate, antioxidants like glutathione and glutathione disulphide (Csandl et al., 2016; Basu et al., 2017; Fallatah and Georges, 2017). Noteworthy, Glutathione (GSH) has 
an impact on ABCC1 transport activities (Nasr et al., 2020). $\mathrm{ABCC} 1$ and $\mathrm{GSH}$ are synergistic to some extent. They cotransport anticancer drugs such as doxorubicin, vincristine and etoposide. ABCC1 also transports GS-conjugated anions such as LTC4 and reduced GSH with low affinity and GSSG with a higher affinity (Leier et al., 1994; Drozd et al., 2016; Zhang et al., 2016; Gana et al., 2019). Exogenous substrates include many natural products like flavonoids, vincristine, daunorubicin, doxorubicin, imatinib, methotrexate and organic anions, metabolites of drugs (Zhou et al., 2008; Whitt et al., 2016). Importantly, the MYCN oncogene, a driver of tumorigenesis in neuroblastoma, can regulate $\mathrm{ABCC} 1$ drug transporter at the level of transcription (Weiss et al., 1997; Porro et al., 2010; Henderson et al., 2011).

\section{STRUCTURE AND FUNCTION}

The ABC transporter family is divided into 7 subfamilies according to their genome sequences and core TMDs (transmembrane domain) structures (Taylor et al., 2017). The three transporters we discuss here belong to the type III $\mathrm{ABC}$ system, for they all consist of $2 \times 6 \mathrm{TMs}$ (transmembrane helix), a striking difference between the type I ABC systems with a minimal core of $2 \times 5$ transmembrane helices (TMs) and type II ABC systems harboring $2 \times 10$ TMs (Parcej and Tampé, 2010; Braunová et al., 2019). Except from ABCC1, ABCB1 and ABCG2 are both half-transporters, working as a homodimer. Two NBDs dimerize to form two ATPase binding sites, which catalyze the ATP hydrolysis following a common mechanism: a glutamate residue interacts with hydrolytic water for the attack of the ATP phosphate (Moody et al., 2002; Oldham and Chen, 2011; Weigl et al., 2018). In NBD1 of ABCC1, the corresponding residue is not a glutamate but an aspartate whose side chain is not long enough to interact with the hydrolytic water (Geourjon et al., 2001).

\section{ABCB1}

ABCB1 has been viewed as a "hydrophobic vacuum clearer" (Waghray and Zhang, 2018) because most of the substrates transported by this protein are hydrophobic and distributed into the lipid bilayer (Gatlik-Landwojtowicz et al., 2006). Each ABCB1 contains 1 TMD, 1 nucleotide binding domain (NBD), and forms an active transporter through dimerization. The specific binding site is located in the TMDs and the ATP hydrolysis occurs in the intracellular NBDs (Alam et al., 2019). In the apo state, the portals open to the cytoplasm and the inner leaflet of the lipid bilayer (Figure 1A). The portals are large enough to accommodate the potential substrates from the lipid bilayer and allow these hydrophobic compounds to pass through. The portals are formed by the proximity TMs (TM4/6, TM10/12). Most of the amino acid residues in the binding pocket are hydrophobic and located in the upper side of the pocket. Only 15 of the 80 residues are polar and located in the lower half of the pocket (Dawson and Locher, 2006). Different substrates or inhibitors, due to their different structures, may bind to different residues. Paclitaxel (Taxol) interacts with residues Q725, Q347, Q990 while zosuquidar interacts with M985,
F982 (Alam et al., 2018; Alam et al., 2019). The conserved glutamine Q475 in NBD1, Q1118 in NBD2 can coordinate with $\mathrm{Mg}^{2+}$ and gama-phosphate of ATP, thus they play an important role in ATP hydrolysis and drug transport (Kim and Chen, 2018) (Figure 1B). In addition, tyrosine residues also play an important role as hydrogen bond donors and acceptors in ABCB1 drug transport activity. To evaluate the importance of the hydrogen bond in ligand-protein interactions, 15 conserved residues interacting with substrates are substituted with tyrosine residues. This so-called $15 \mathrm{Y}$ mutants can still transport small and medium size substrates, however, large substrates like Bodipy-Vinblastine cannot be normally transported. This demonstrates that in some cases it is not the hydrogen bond but the physico-chemical properties which affect the transportation (Vahedi et al., 2017).

\section{ABCG2}

ABCG2 is a half transporter, with 6 transmembrane helixes and 1 ATP-binding site. The high-resolution structure which was first elucidated in 2017 (Taylor et al., 2017; Figure 2A) brings an insight of the molecular mechanisms underlying the transport behavior. ABCG2 has $1 \mathrm{NBD}$ and 1 TMD located on a single polypeptide chain and forms a homodimer as an active transporter. Unlike ABCB1 transporter, the distance between the NBDs and the membrane within the ABCG2 is smaller due to the shorter transmembrane helix and intracellular loops (Locher et al., 2002; Woo et al., 2012). The interface of TMD is formed by TM2 and TM5a from opposing ABCG2 monomers (Taylor et al., 2017). ABCG2 has two cavities involved in the transport behavior (Figure 2B). The larger cavity 1 and the smaller cavity 2 are separated by two leucine (L554, L554') motifs (Khunweeraphong et al., 2017; Jackson et al., 2018; Manolaridis et al., 2018). Cavity 1 opens to the cytoplasm and inner leaflet of the lipid bilayer, and cavity 2 opens to the extracellular, which is located below the EL3 external loop (Khunweeraphong et al., 2019). The function of cavity 1 is to accommodate potential substrates, especially the flat, polycylic and hydrophobic ones, while cavity 2 possesses lower affinity for these substrates because of its less pronounced hydrophobic interface (Orlando and Liao, 2020). However, the lower affinity may release substrates more easily (Taylor et al., 2017). Two critical steps are involved in the process of substrate transport. Firstly, the di-leucine valve regulates the small molecules to enter the upper cavity, which is a key element for the catalytic cycle. Secondly, the essential residue E585 are harbored by the re-entry helix in the roof, making it more accessible to the extracellular (Khunweeraphong et al., 2019). The mutants N436A, F439A decrease both the substrate transport activity and ATPase activity which proves the functions of these two residues in binding and transporting estrone-3-sulfate (E1S) (Figure 2C). Moreover, the hydrogen bond between N436 and the sulfate group of E1S and the stacking interaction between the phenyl ring of F439 and the ring system of E1S are important for binding affinity. Another mutant V546F reduces the transport activity but simultaneously increases the ATPase activity, indicating that the addition of two phenyl rings at this position mimics the binding of a substrate and stimulates the 


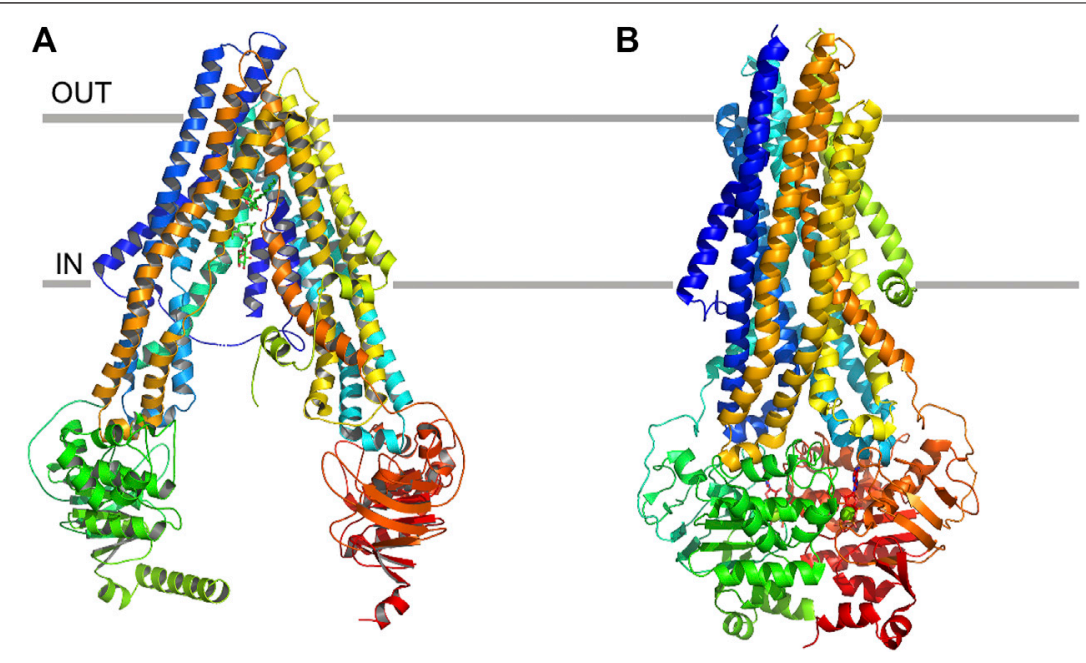

FIGURE 1 | Ribbon representation of the ABCB1 structure. (A) apo state of ABCB1, and (B) ATP-binding state of ABCB1.

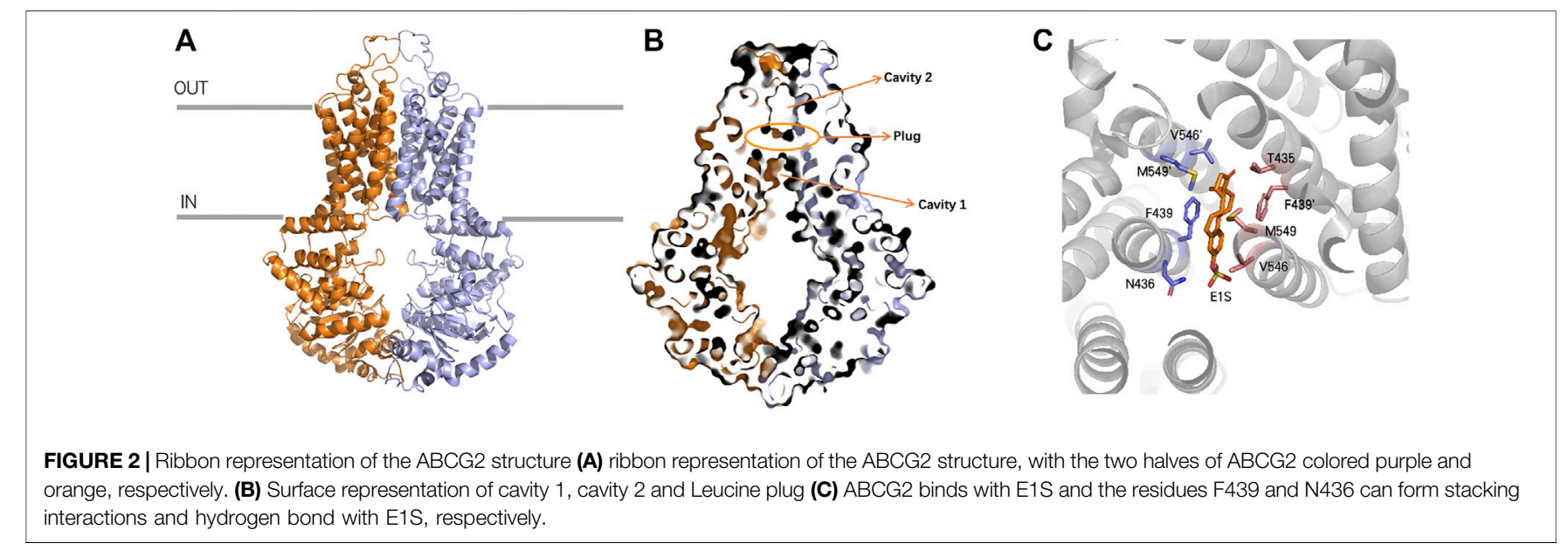

ATPase activity, but can cause "clog" upon binding with E1S (Manolaridis et al., 2018).

\section{ABCC1}

$A B C C 1$ transporter is encoded by $A B C C 1$ gene, with the weight of $190 \mathrm{kDa}$ and contains 1580 amino acids (Cole et al., 1992). Although there is a $23 \%$ sequence identity between P-gp and $\mathrm{ABCC} 1$, they have an intriguing substrate overlap. ABCC1 is a single polypeptide, containing transmembrane domains (TMDs) and two nucleotide-binding domains (NBDs) (Johnson and Chen, 2017). Only the one nucleotide-binding domain located on the NBD2 is responsible for hydrolyzing ATP and providing energy for translocation (Conseil et al., 2019). ABCC1 contains a $\mathrm{N}$-terminal membrane-bound region (TMDo) domain that links to the transporter core through a Lo linker (Figure 3A). The truncation of TMDo behaves like wildtype (Bakos et al., 1998; Johnson and Chen, 2017), whereas the loss or mutation of Lo linker results in false protein folding and defective function (Bakos et al., 1998; Bakos E et al., 2000;
Bakos É et al., 2000). The binding pocket of ABCC1 transporter is formed by two bundles, TM1 and TM2, and the inner-face residues provided by these two bundles are quite different (Conseil et al., 2019). Positively charged residues locate in TM1 while hydrophobic residues locate in TM2. The positive charged region usually binds with the moiety of GSH and another region rich in hydrophobic residues binds to the substrate (Johnson and Chen, 2017). LTC4 can be selectively transported by ABCC1 (Figures 3B,C) and the way in which LTC4-GSH conjugates to pass through ABCC1 has been elucidated by several studies (Loe et al., 1996; Liening et al., 2016; Conseil et al., 2019). Amphipathic substrates that contain both negatively charged and hydrophobic residues can be transported without conjugating with GSH. Besides MYCN oncogene regulates the transcription of ABCC1, the transfection of MCF-7/VP16 breast cancer cells with miR-326 can downregulate ABCC1 expression and increase cancer cell sensitivity to etoposide and doxorubicin (Liang et al., 2010). 


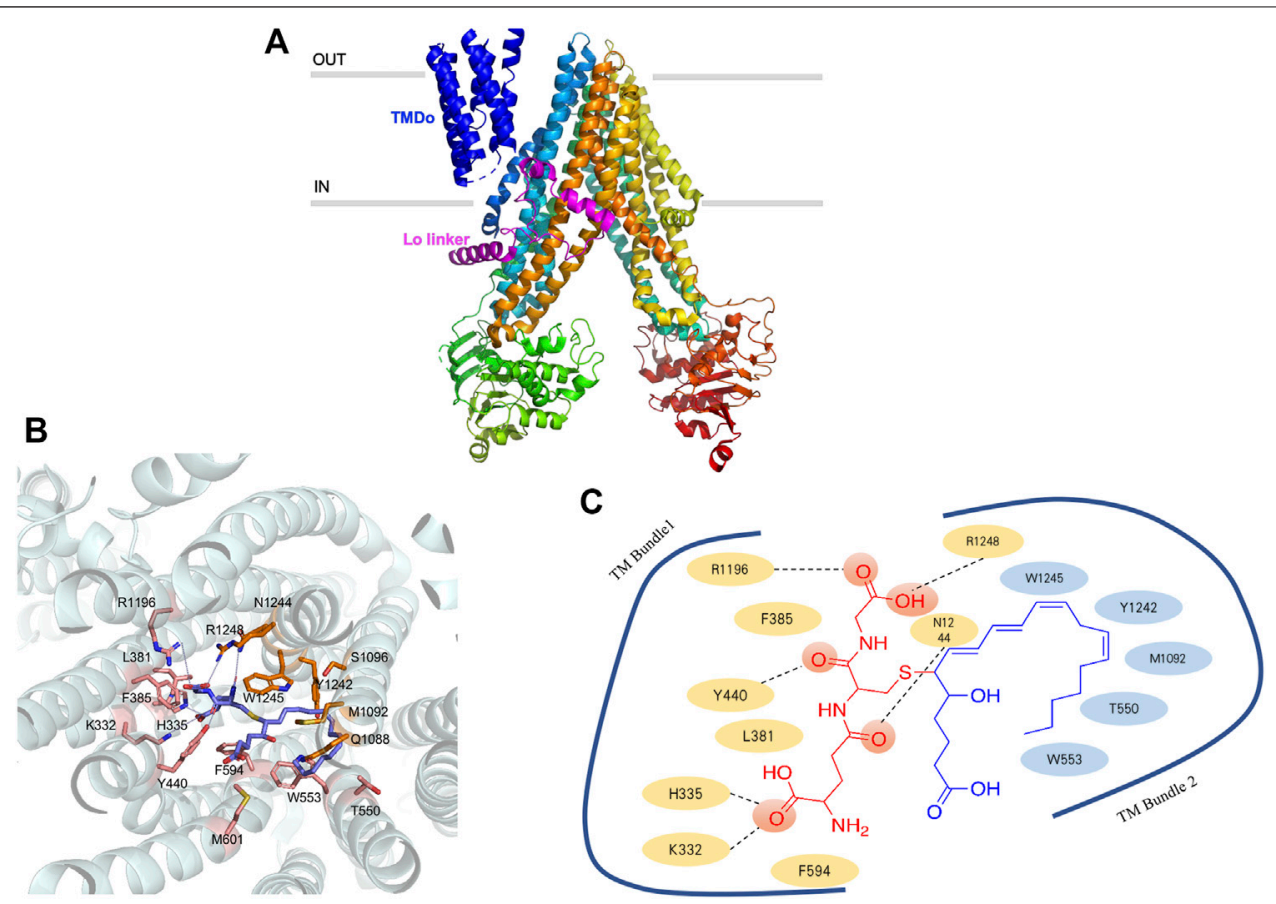

FIGURE 3 | Ribbon representation of the ABCC1 structure (A) ribbon representation of the ABCC1 structure, with the TMDo colored dark blue and Lo linker colored purple (B) three-dimension of ABCC1 binding with LTC4, the proximity residues, and their interactions with LTC4 are annotated in the picture (C) the systematic illustration of ABCC1 binding with LTC4.

\section{ABC TRANSPORTER INHIBITORS}

The past few decades have seen numerous efforts made to solve the drug resistance caused by $\mathrm{ABC}$ transporter proteins. Many of the first and second-generation $\mathrm{ABC}$ transporter inhibitors exhibit either high levels of toxicity or low potential inhibiting effects (Adamska and Falasca, 2018). Researchers are exploiting more potent inhibitors, mainly focusing on synthetic compounds and chemicals from nature plants. The chemical structures of representative $A B C$ inhibitors are shown in Figures 4-6.

\section{P-GP INHIBITORS}

\section{Natural Products Flavonoids}

Majority of flavonoids are inhibitors of P-gp (Boumendjel et al., 2002; Falcone Ferreyra et al., 2012) and their inhibitory mechanisms are different, such as blockage of the binding site (Nabekura et al., 2008), interference with ATP hydrolysis (Shapiro and Ling, 1997), decrease of P-gp expression (Sun et al., 2013). Naringenin (1), isolated from the aerial parts of Euphorbia pedroi, exhibits multiple cellular functions such as antioxidant, anti-inflammatory, P-gp inhibitory activities (Chen et al., 2019). Upon applying together with felodipine in KB-V1 cells, it can decrease the P-gp expression level in KB-V1cells and increase the concentration of felodipine (Surya Sandeep et al., 2014). Quercetin (2), which is abundant in onions, apples, broccoli and berries, has a wide range of biological activities including antiproliferation and proapoptotic actions with cancer cells. Used in combination with the chemotherapeutic agent daunorubicin in gastric cancer cells, quercetin can downregulate the ABCB1 gene, reduce the overexpression of P-glycoprotein, and inhibit the efflux of drugs. Finally, quercetin significantly sensitizes cancer cells to action of daunorubicin and increases the percentage of apoptosis (Borska et al., 2012). Another study found that methylated EGC and GC derivatives (3) exhibited better inhibitory effects targeting ABCB1 with an EC50 range from 102 to $195 \mathrm{nM}$, meanwhile they are not the substrates of ABCB1(Wong et al., 2015). Chalcones are precursors for the synthesis of flavonoids, which can also reverse multidrug resistance (Yin et al., 2019). $2^{\prime}, 4^{\prime}$-Dihydroxy-6'-methoxy- $3^{\prime}, 5^{\prime}$-dimethylchalcone modulates the expression of P-gp gene. When combined with 5fluorouracil (5-FU), it can significantly elevate tumor inhibition rate to $72.2 \%$ in BEL-7402/5-FU cell lines (Huang et al., 2012). SAR studies demonstrate that the introduction of a basic group on the chalcone moiety could enhance the P-gp inhibition and weaken the BCRP inhibition. The basic chalcones are better P-gp inhibitors, while the non-basic chalcones are better BCRP inhibitors. The good activity of chalcone is mainly related to properly placed electron donor atoms rather than lipophilicity, especially the meta-disubstituted dimethoxy motif on either ring A or B (Figure 7; Liu et al., 2008).

\section{Alkaloids}

Alkaloids are secondary metabolites found in plants, fungi, and bacteria. The main structural feature of alkaloids is a heterocyclic 


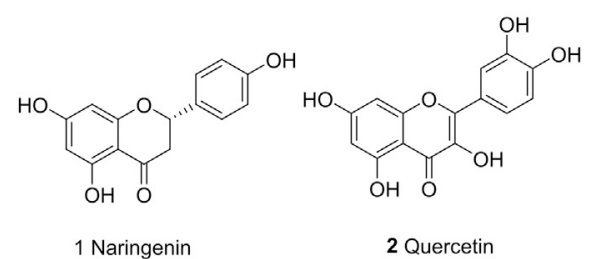<smiles></smiles><smiles>C=CC1CN2CCC1C2(O)c1ccnc2cc(OC)ccc12</smiles><smiles></smiles><smiles>COc1ccc2cc3c(cc2c1)CCN1CCOCC1=C3</smiles><smiles>COc1cc(CC2CN(C)C(Cc3ccc(Oc4ccc(O)cc4)cc3)c3cc(OC)c(OC)cc32)ccc1O</smiles><smiles>COc1ccc(CC2c3c(cc(OC)c(OC)c3OC)CCN(C)C2Cc2ccc(OC)cc2)cc1</smiles><smiles>COc1ccc(CCN(C)CCC(C#N)(c2ccc(OC)c(OC)c2)C(C)C)cc1OC</smiles>

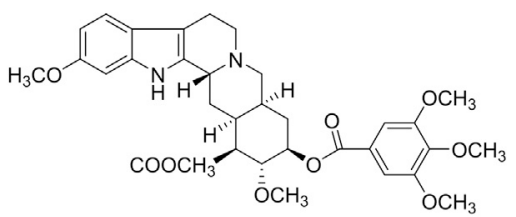

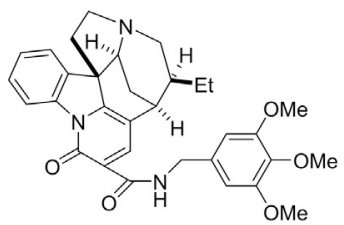

10 Reserpine

11 3,4,5-trimethoxybenzyl leuconicine A<smiles>COc1ccc(C(=O)Cn2cc(-c3ccc(O)cc3)c(-c3ccc(O)cc3)c2C(C)=O)cc1</smiles><smiles>CC1=C(C(=O)NCCN2CCCC2)C(=Cc2cc3cc(Br)cnc3[nH]c2=O)C(=O)N1</smiles><smiles>COc1cc2c(cc1OC)CN(C(=O)CC=Cc1ccc3c(c1)OCO3)CC2</smiles>

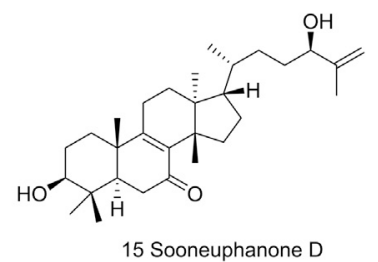

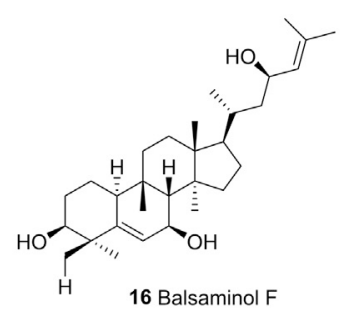

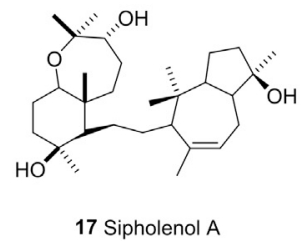

FIGURE 4 | The chemical structures of representative P-gp inhibitors.

ring bearing one or more basic nitrogen. Such nitrogen atom is necessary for P-gp inhibitory activity (Qiu et al., 2014). Quinine (4), is reported to reverse doxorubin resistance in 8226/DOX6 myeloma cells and the quinine dimer can reverse the Rh123 efflux in MCF-7/DX1 cells through P-gp inhibition. Further modifications focus on the variations of the linker within the dimer and the introduction of triazole ring systems (Pires et al., 2009). Sanguinarine (5) is a benzylisoquinoline that can increase the bax/bcl2 ratio, thereby activating caspases to reverse the P-gpinduced drug resistance (Eid et al., 2012). Berberine (6) is a calcium channel blocker, which can inhibit the Wnt signaling pathway and P-gp so as to increase the intracellular accumulation of drugs (Zhang et al., 2019). Berbamine (7) can downregulate the mRNA of P-gp in imatinib-resistant BCR-ABL-positive human leukemia K562 (K562-r) cells (Wei et al., 2009). Tetrandrine (8), a bisbenzyl isoquinoline, can regulate NF- $\kappa B$ signaling pathway and inhibit P-gp in MCF-7/ADR cell lines when synergistically used with paclitaxel as self-assembled nanoparticles (Jiang et al., 2017). Verapamil (9), a papaverine derivative, is a classic chemosensitizer and the first found P-gp inhibitor. It can competitively inhibit the transport function of P-gp without interrupting ATP hydrolysis, and increase the intracellular accumulation of many anticancer drugs to overcome the P-gpmediated MDR (Wang and Sun, 2020).

Indole alkaloids such as Reserpine (10), Indole-3-carbinol and indole-3-carbaldehyde can inhibit P-gp mediated efflux of drugs like doxorubicin, vincristine (Henrich et al., 2006; Wei et al., 2012). 3,4,5-trimethoxybenzyl leuconicine A (11), a derivative of 
<smiles>O=C1C[C@H](c2ccc(O)cc2)Oc2cc(O)cc(O)c21</smiles>

1 Naringenin<smiles>O=C1C=C(c2ccccc2)Cc2cc(O)cc(O)c21</smiles>

18 Chrysin

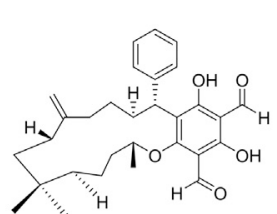

19 Guajadial

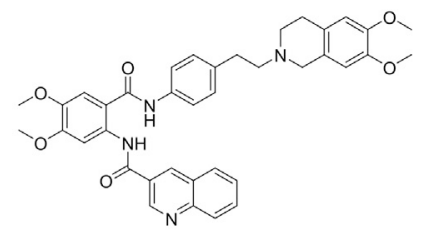

20 Tariquidar

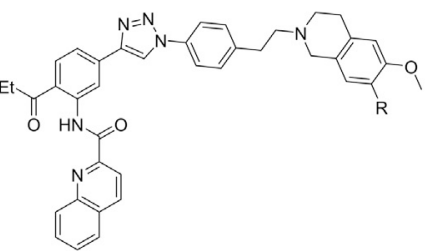

21 UR-MB108:R=OMe 22 UR-MB136: $\mathrm{R}=\mathrm{O}\left(\mathrm{CH}_{2} \mathrm{CH}_{2} \mathrm{O}\right){ }_{3} \mathrm{Me}$

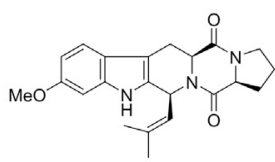

23 Fumitremorgin C

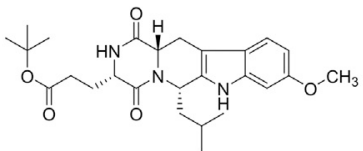

$24 \mathrm{~K} 0143$

FIGURE 5 | The chemical structures of representative ABCG2 inhibitors<smiles>COc1cc(OC)c2c(=O)cc(N3CCN(Cc4ccc5nonc5c4)CC3)oc2c1</smiles>

25 2- [4-(Benzo[c][1, 2,5]oxadiazol-5 ylmethyl)piperazin-1-yl]-5,7-

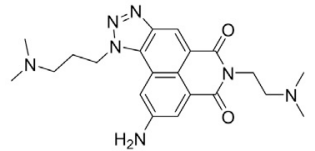

27 LSS-11

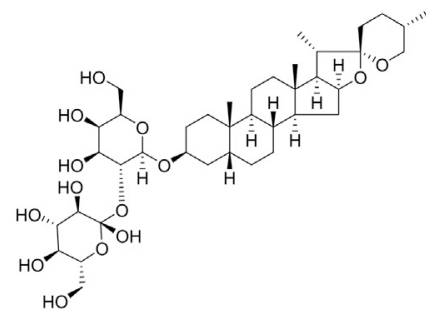

26 Timosaponin A-III<smiles>O=c1cc(-c2ccccc2)oc2cc(O)cc(O)c12</smiles>

18 Chrysin

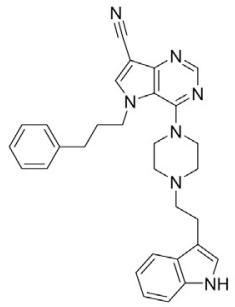

28 4-(4-(2-(1H-Indol-3yl)ethyl)piperazin-1-yl)-5-(3phenylpropyl)-5H-pyrrolo[3, d]pyrimidine-7-carbonitrile

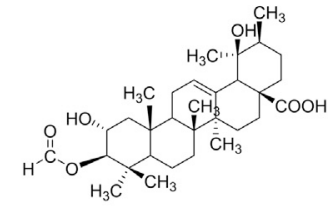

29 3ß-Acetyl tormentic acid

FIGURE 6 | The chemical structures of representative ABCC1 inhibitors.

leuconicine $\mathrm{A}$, is a potent $\mathrm{P}$-gp inhibitor as it decreases the dose of vincristine in a resistant cancer cell lines (Munagala et al., 2014).

Lamellarin $\mathrm{O}$ (12), isolated from southern Australian marine sponge, possesses inhibitory effects on both P-gp and ABCG2. It increases the accumulation of $\mathrm{P}$-gp transporting drugs like DOX in SW620/DOX300 cells through the blockage of the binding site
(Huang et al., 2014). Cyanogramide bearing a novel spirocyclic pyrrolo [1,2-c]imidazole skeleton, which is isolated from Actinoalloteichus cyanogriseus WH1-2216-6 can reverse the DOX-induced resistance in K562/A02 and MCF-7/DOX cells, the vincristine (VCR)-induced resistance in KB/VCR cells (Fu et al., 2014) with moderate activities in micro-molar range. A 


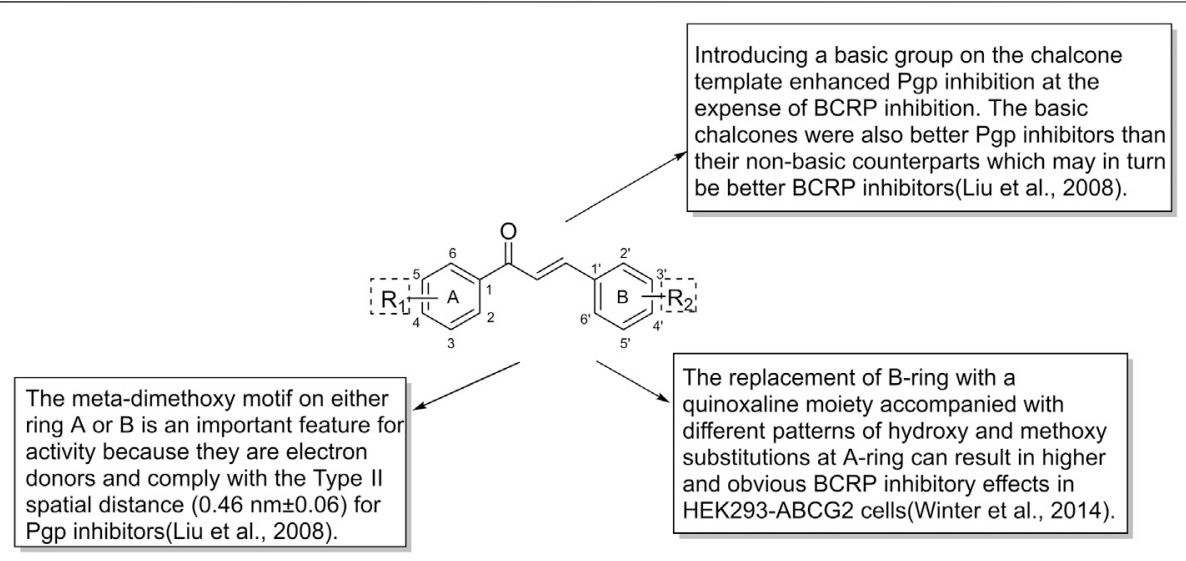

FIGURE 7 | The structure-activity relationship of chalcones as ABC transporter inhibitors.

series of 5-halogenated-7-azaindolin-2-onederivatives containing a 2,4-dimethylpyrrole moiety are evaluated for their anticancer effects in MCF-7, HepG2, HT-29, A549, PANC-1, Hela. The most active one (13), $\left.\mathrm{IC}_{50} \mathrm{~s}: 4.49-15.39 \mu \mathrm{M}\right)$ was proved to be even more potent than Sunitinib $\left(\mathrm{IC}_{50} \mathrm{~s}: 4.70->30 \mu \mathrm{M}\right)$ against all tested cancer cell lines (Wang $M$ et al., 2015). Another polysubstituted pyrrole, 4-acetyl-3- (4-fluorophenyl)- 1(p-tolyl)-5-methylpyrrole, was found to reverse digoxin with a $\mathrm{IC}_{50}$ value of $11.2 \mu \mathrm{M}$ and enhance the pharmacokinetic properties of P-gp substrates (Bharate et al., 2015). Piperine, a piperidine alkaloid from Indian spice black pepper, can downregulate the expression level of transporter $\mathrm{ABCB} 1$, ABCC1, and ABCG2 genes (Manayi et al., 2018). Piperine mainly inhibits $\mathrm{P}$-gp activity by interacting with its nucleotide binding domain, that is to say, it competes with ATP binding site in P-gp (Singh et al., 2013). Take this into consideration, two piperine analogs Pip1 (14) and Pip2 were synthesized and exhibited better interaction with P-gp than piperine (Syed et al., 2017). Tertiary alkaloids like stemocurtisine and oxystemokerrine, isolated from Stemona aphylla and Stemofoline burkillii, also can inhibit P-gp to some extent. Stemofoline can inhibit P-gp of human cervical carcinima cell line $(\mathrm{KB}-\mathrm{V} 1)$ in a dose and time-dependent manner (Chanmahasathien et al., 2011).

\section{Terponoids}

Terponoids can be divided into several types according to the number of isoprene units within their parent structure like monoterponoids (bearing $10 \mathrm{C}$ ), diterponoids (bearing $20 \mathrm{C}$ ), sesquiterponoids (bearing $15 \mathrm{C}$ ), tetraterpenes (bearing $40 \mathrm{C}$ ). Studies have shown that lipophilic substituents at C6 position and the carbonyl group at $\mathrm{C} 2, \mathrm{C} 3, \mathrm{C} 8$ positions are required to make terponoids ideal P-gp inhibitors (Kumar and Jaitak, 2019).

Sooneuphanone D (15), isolated from Euphorbia soongarica, is a potent P-gp inhibitor with a remarkable MDR reversal activity much higher than verapamil. When sooneuphanone $\mathrm{D}$ is applied together with navelbine, it can significantly reduce the $\mathrm{IC}_{50}$ values of navelbine within KBV200 cell lines, indicating its reversal effects in P-gp overexpressed cancer cell lines (Gao and Aisa,
2017). In another study, 28 cucurbitane-type triterponoids, isolated from Momordica balsamina and their derivatives were studied for their collateral sensitivity effect on three different human cancer entities. Balsaminol F (16) exhibits collateral sensitivity effect through high anti-proliferative activity in gastrolic cancer cell lines (EPG85-457). Its derivatives such as balsaminagenin $\mathrm{C}$ exhibit reversal of multidrug resistance in human MDR1 gene-transfected mouse lymphoma cells (Ramalhete et al., 2016; Ramalhete et al., 2018). A myrsinol diterpene J196-10-1, isolated from LANGDU, exhibits reversal effects through competitively inhibiting P-gp transporters and increasing intracellular drug accumulation without altering MDR1 gene expression (Wang et al., 2016). Sipholenol A (17), isolated from Red Sea Sponge Callyspongia siphonella, mediates drug efflux activities of P-gp without altering the expression level of P-gp. Substitution of the methyl group at $\mathrm{C} 15$ and the oxidation of the hyroxyl group to a ketone at $\mathrm{C} 4$ can both cause reduced reversal activity (Jain et al., 2007; Shi et al., 2007).

\section{ABCG2 INHIBITORS}

\section{Natural Product Flavonoids}

Naringenin (1) is a common dietary flavanone which can be found in citrus fruits like oranges, bergamots and lemons (Ferreira et al., 2018). Naringenin and its derivatives were evaluated as multidrug resistance (MDR) reversers in cancer cells. The carbonyl group of naringenin was modified into hydrazones, azines, carbohydrazides which contain nitrogen atom or extra aromatic moieties. Azines and carbohydrazide derivatives exhibit potent efflux inhibition. Among them, the azine derivatives exert high inhibitory activity due to the introduction of $\mathrm{C}=\mathrm{N}-\mathrm{N}=\mathrm{C}$ moiety and have dual inhibition on both ABCG2 and ABCC1 (Ferreira et al., 2018). Chrysin (18) shows inhibitory activities toward ABCG2 with an $\mathrm{IC}_{50}$ of $4.6 \pm$ $0.5 \mu \mathrm{M}$, while tectochrysin and 6-prenylchrysin exhibit inhibitory activities in R482 ABCG2-transfected HEK-293 cells with an $\mathrm{IC}_{50}$ of $3.0 \pm 0.9 \mu \mathrm{M}$ and $0.29 \pm 0.06 \mu \mathrm{M}$, respectively. In general, 
flavones inhibit ABCG2 more efficiently than flavonols, isoflavones and flavanones (Ahmed-Belkacem et al., 2005). As mentioned earlier, introducing different groups on the chalcone template can produce corresponding inhibitory effects on P-gp and BCRP. With respect to chalcone derivatives, the replacement of B-ring with a quinoxaline moiety accompanied with different patterns of hydroxy and methoxy substitutions at A-ring can result in higher and obvious BCRP inhibitory effects in HEK293ABCG2 cells (Winter et al., 2014). The quinoxaline contributes the electrostatic interactions between the two nitrogen atoms and the ABCG2 protein (Kraege et al., 2016b). There are four key structural features that improve the ABCG2 inhibition: the orthoposition of the amide linker; the presence of a phenyl or 2-thienyl substitution at the amide linker; 3,4-dimethoxy substitution on ring B (Kraege et al., 2016a; Kraege et al., 2016c; Silbermann et al., 2019; Yin et al., 2019).

\section{Terponoids}

Guajadial (19), isolated from the leaves of Psidium guajava, is a natural meroterpenoid which has been found to have anti-tumor activity, especially in breast cancer cell lines. Guajadial has reversal effects in MCF-7/ADR and MCF-7/PTX cells by inhibiting both expressions of P-gp and ABCG2. Meanwhile, it suppresses the PI3K/Akt pathway, which is related to cell proliferation, apoptosis, and migration (Li et al., 2019).

\section{Tariquidar Analogs}

Tariquidar (20) was an intrinsically the third-generation P-gp inhibitor which can reverse the resistance of doxorubicin, vinblastine in advanced breast cancer (Durante et al., 2017). However, due to its high toxicity in a phase III clinical trial for non-small cell lung cancer (NSCLC) (Nobili et al., 2006) and susceptibility to hydrolysis, a large number of tariquidar analogs have been synthesized to optimize its pharmacological properties. In a recent study, researchers synthesized a series of tariquidar derivatives and found that some of them are able to reverse both ABCB1 and ABCG2-mediated drug efflux, respectively. The mechanism may be related to the inhibition of ATP hydrolysis, but needs to be further verified by ATPase assay (Teodori et al., 2017). The unstable ester moiety was further replaced by ketones, which increase the stability in mouse plasma. UR-MB108 (21) and UR-MB136 (22) are the most effective ABCG2 inhibitors so far with the IC50 value about $80 \mathrm{nM}$ in a Hoechst 33,342 transport assay. The molecular mechanism of their inhibitory effects lies in the depressing of ATPase by locking the inward-facing conformation (Antoni et al., 2020).

\section{Ko143 Analogs}

The fungal toxin fumitremorgin $\mathrm{C}(23, \mathrm{FTC})$ is a specific inhibitor targeting ABCG2, however, the neurotoxicity prevents its further use (Allen et al., 2002). Later, tetracyclic analogs of FTC were developed, among which Ko143 (24) was found to be the most potent one, but it is unstable in mouse plasma and has nonspecific effects on $\mathrm{ABCC} 1$ and $\mathrm{ABCB} 1$. These have led to further structural study of ABCG2 and the development of Ko143 analogs as specific ABCG2 inhibitors (Weidner et al., 2015). Ko143 analogs are as potent as or even superior than Ko143.
The modifications at C-9 position with methoxy group forms a hydrogen bond with T435 in cavity 1 . The removal of methoxy groups and addition of small hydrophilic groups reduce the binding energy, while small hydrophobic groups do not make any differences. The tert-butyloxycarbonyl group, which can form van der Waals interactions with residues at C-3 position, also leads to decreased inhibitory effects when exchanged with ion-bearing moieties (Jackson et al., 2018).

\section{ABCC1 INHIBITORS}

\section{Natural Products \\ Flavonoids}

Flavonoids-type compounds can also exert ABCC1 inhibitory activity in MDCKII-MRP1 cells. Chromones bearing substituted amino groups with $\mathrm{N}$-substituted carboxamide moieties in C-2 are synthesized and tested for their inhibitory activities, among which (2- [4-(Benzo [c] $[1,2,5]$ oxadiazol-5-ylmethyl)piperazin-1-yl]-5,7-dimethoxy-4H-

chromen-4-one (25) is proved to be the most potent ABCC1 inhibitor and stable in mouse plasma (Obreque-Balboa et al., 2016; B et al., 2020). In another study, flavonoid dimers are found to be more potent toward ABCC1 than their counterpart monomers (Dury et al., 2017). Three flavono stilbenes isolated from Sophora alopecuroides $L$ were found to have an inhibitory effect toward ABCC1, which can increase the intracellular concentrations of 6-carboxyfluorescein diacetate and doxorubicin in MRP1-transfected U-2 OS cells (Ni et al., 2014). Timosaponin A-III (26, TAIII), a saponin isolated from the rhizome of Anemarrhena asphodeloides, were found to reverse both $\mathrm{P}$-gp and ABCC1-induced drug resistance through regulation of $\mathrm{PI} 3 \mathrm{~K} / \mathrm{Akt}$ signaling pathway (Chen J-R et al., 2016; Gergely et al., 2018). Chrysin (18), 3-methoxy-chrysin and 5,7-dihydroxy-4'fluoro-flavone are more effective and less toxic than verapamil. Hydroxylation at different places of chrysin can alter the activity, for example, hydroxylation at C-5 or C-7 can increase GSH efflux, while hydroxylation at C-6 leads to the opposite results. However, when hydroxylation occurs both at C-5 and C-7, the activity does not increase (Lorendeau et al., 2014). In general, structure-activity relationships demonstrated that although the absence of a hydroxyl group at $\mathrm{C}-3$ of flavonoid $\mathrm{C}$ ring is absolutely required to induce ABCC1-cell death, but it cannot to stimulate GSH efflux (Lorendeau et al., 2014).

\section{Alkaloids}

The inhibitory effects of pyrrolo [3,2-d]pyrimidines toward ABCC1 show that piperazine, which bears large phenylalkyl side chains at C-4 position, can increase the inhibitory activities, whereas when piperazine is replaced with an amino group, the activity decreases. Moreover, the aliphatic and aliphatic aromatic variations in C-5 and C-6, especially the large aliphatic side chain at position 5, can inhibit ABCC1 effectively with $\mathrm{IC}_{50}$ value in the nanomolar range (Figure 8; Schmitt et al., 2016). A novel triazolonaphthalimide derivative 
The aliphatic and aliphatic-aromatic variations at position 5 and 6 , especially large aliphatic side chain at position 5, can inhibit $A B C C 1$ effectively(Schmitt et al., 2016).

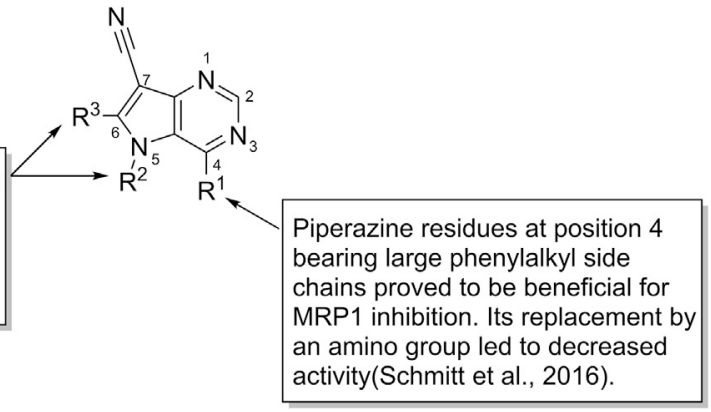

FIGURE 8 | The structure-activity relationship of pyrrolo [3,2-d]pyrimidines.

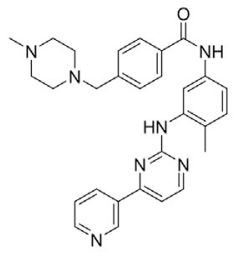

30 Imatinib

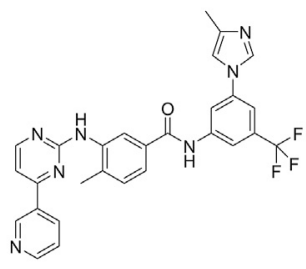

31 Nilotinib

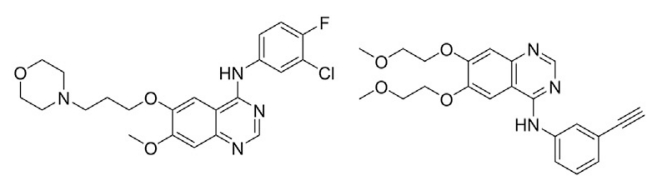

33 erlotinib

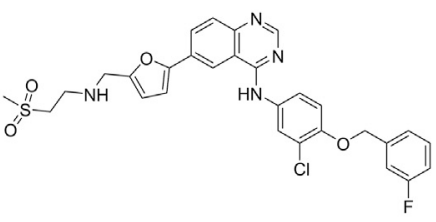

34 lapatinib<smiles>CC(=O)C1C(C)=NC(=O)C1C</smiles>

35 Sunitinib

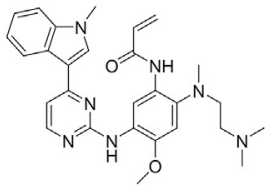

36 Osimeritinib

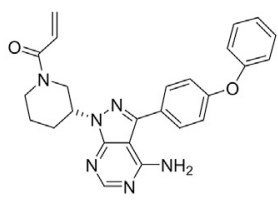

37 Ibrutinib

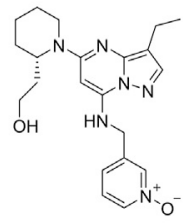

38 Dinaciclib

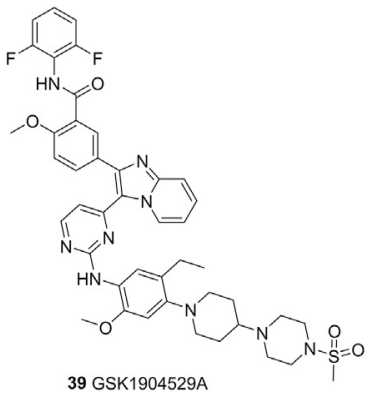

39 GSK1904529A

FIGURE 9 | The chemical structures of representative tyrosine kinase inhibitors.

named LSS-11 (9-amino-6-(2-dimethylamino)propyl]-1-(3(dimethylamino)-propyl)benzo [de] [1,2,3]triazolo [5,4-g] isoquinoline-5,7(1H, $6 \mathrm{H})$-dione (27) acts as a potent inhibitor toward ABCC1 through DR5/PARP1 pathway and STAT3/ MDR1/MRP1 STAT3 inhibition (Ji et al., 2017). Recently, a series of 9-deazapurines are synthesized (Figure 8), among which the 4-(4-(2-(1H-Indol-3-yl)ethyl)piperazin-1-yl)-5-(3phenylpropyl)-5H-pyrrolo [3,2-d]pyrimidine-7-carbonitrile (28), has been identified to be a broad-spectrum inhibitors which regulate P-gp-mediated efflux of Calcein AM, ABCC1mediated efflux of daunorubicin, and ABCG2-mediated efflux of pheophorbide A (Stefan et al., 2017). 


\section{Other Inhibitors}

$3 \beta$-Acetyl tormentic acid (29) can reverse the resistance of doxorubicin and vincristine by mediating intracellular levels of GSH and inhibition of glutathione-s-transferase (GST) activity, instead of modulating the expression of ABCC1(Rocha Gda et al., 2014).

\section{TYROSINE KINASE INHIBITORS}

TKIs bind to the catalytic domain of tyrosine kinases and inhibit cross-phosphoralation and thereby interfere downstream signaling pathways, subsequently impairing cell proliferation and survival. The mechanism underlying the inhibitory effects of TKIs on $\mathrm{ABC}$ transporters may be similar to that of tyrosine kinase, that is, they compete with ATP and bind to the ATPbinding sites (Wang et al., 2015). Whether TKIs are substrates or inhibitors of $\mathrm{ABC}$ transporters depends on their concentrations and the cancer cells they target (Figure 9).

\section{Imatinib and Nilotinib}

Imatinib (30) is a kinase inhibitor which targets BCR-ABL (BCR, break point cluster region; $\mathrm{ABL}$, Abelson virus tyrosine kinase). Studies revealed that imatinib could reverse the drug resistance to doxorubicin by downregulating expression level of ABCB1 and subsequently resulting in accumulation of doxorubicin (Sims et al., 2013). Imatinib also exhibits inhibitory effects toward ABCG2 even at low concentration and the expression level of ABCG2 did not affect the efflux and accumulation of imatinib, which indicates that imatinib may have a higher affinity for ABCG2 than ABCB1(Ozvegy-Laczka et al., 2004). Nilotinib (31), an aminopyrimidine ATP-competitive second-generation TKI, was designed to overcome resistance to imatinib in many BCR-ABL mutants (Sacha and Saglio, 2019). It exhibits reversal effects in the doxorubicin-resistant MG63/DOX cell line (Zhou et al., 2016). Moreover, it specifically reverses mitoxantrone efflux caused by ABCG2 and increases the intracellular accumulation of mitoxantrone in over-expressing ABCG2 cells (Jordanides et al., 2006).

\section{Gefitinib, Erlotinib and Lapatinib}

Gefinitib (32), one of the most famous EGFR inhibitors, has been used to treat NSCLC. However, enhanced ABCG2 expression has been detected within gefinitib-resistant cancer cells (Chen et al., 2011; Hegedüs et al., 2012). Inhibition of EGFR by erlotinib (33) can also induce the alteration in ABCG2 gene and protein expression level, supporting the fact that EGFR/AKT pathway is involved in the regulation of ABCG2 expression (Porcelli et al., 2014). What is more, a synergistic effect of lapatinib (34) and doxorubicin was also found in tumorspheres which generates from human breast cancer cells and exhibits drug resistance due to the overexpression of $\mathrm{ABCB} 1$ and increased EGFR/HER2 signaling (Lainey et al., 2012; Lainey et al., 2013).

\section{Sunitinib}

Recently, a study has shown that in doxorubicin-resistant endothelial cell lines, the over-expression of ABCG2 and
ABCB1 has a cross-resistant effect on sunitinib (35). The blockage of ABCG2 can result in a restored sunitinib cytotoxic effect (Huang et al., 2015). In another study, RCC cells with ABCG2 overexpression due to the treatment of sunitinib, were treated with elacridar, a dual inhibitor of ABCG2 and ABCB1, resulting in the restored cytotoxicity of sunitinib (Sato et al., 2015). This indicates that sunitinib is mainly transported by ABCG2 and efficient inhibition of ABCG2 is needed in sunitinib-resistant cancer cells.

\section{Other TKIs}

There are dozens of newly found TKIs which efficiently targeted ABC transporters. For example, osimeritinib (36), a thirdgeneration EGFR inhibitor, have been found to reverse the drug resistance within ABCB1-overexpressed bone marrow cells collected from AML patients. Evidences show that osimeritinib can increase the accumulation of Rhodamine 123 (Chen Z et al., 2016). Ibrutinib (37), an inhibitor of Bruton's tyrosine kinase, can increase the accumulation of ABCC1 substrates within ABCC1-overexpressed HEK293/MRP1 and HL60/Adr cells (Zhang et al., 2014). Dinaciclib (38), a cyclindependent tyrosine kinase inhibitor, can decrease the daunorubicin efflux of MDCKII-ABCC1 and human cancer T47D cells, thus exhibit a synergistic effect when coadministrated with other anti-cancer drugs (Cihalova et al., 2015). GSK1904529A (39), an IGF-IR inhibitor, can also increase the intracellular concentration thus enhancing the cytotoxicity of ABCC1 substrate vinblastine in HEK293/MRP1 cells by inhibiting its efflux (Gupta et al., 2017). In general, TKIs have been deeply implicated in counteracting ABC-induced multidrug resistance through ways like inhibiting efflux activity, co-administration with drugs, which provides new opportunities for clinical treatment of multidrug resistance.

\section{CONCLUSION AND PERSPECTIVE}

In recent years, many efforts have been made to modulate these $\mathrm{ABC}$ transporters, thus increase the intracellular concentration of drugs and reverse multidrug resistance (Kathawala et al., 2015). Several chemo-sensitizers were tested in clinical trials, like cyclosporine A, tariquidar, however, they did not show satisfying therapeutic effects due to their high toxicity, drugdrug interactions and clinical trial design problems (Robey et al., 2018). However, there are also novel strategies that can reverse multidrug resistance such as using DNA methyltransferase inhibitors (DNMTi), hypomethylating agents (HMAs) and histone deacetylase inhibitors (HDACi) (Ball et al., 2017). A DNA methyltransferase (DNMT), 5-AC (5-azacytidine) can reverse irinotecan resistance in metastatic CRC patients when combined with irinotecan (Sharma et al., 2017). In a phase II clinical trial, 17 pretreated and platinum-resistant patients with ovarian cancer were re-sensitized to carboplatin after being treated with HDACi (Matei et al., 2012). Expression of ABC transporters can also be regulated by miRNAs. For example, $A B C B 1 / M D R 1$ encoding for P-gp can be downregulated by miR$30 \mathrm{a}$ in advanced gastric cancer and miR-9-3p in CML to reverse 
drug resistance (Li et al., 2016; Li et al., 2017). miR-145 can decrease the level of $A B C C 1 / M R P 1$ and increase cisplatin toxicity in gallbladder cancer (Zhan et al., 2016). miR-490-3p regulates $A B C C 2 / M R P 2$ in ovarian cancer and possibly increases response to cisplatin (Tian et al., 2017). This provides us with an insight for finding other ways to reduce the mortality caused by multidrug resistance. More importantly, efflux of drugs has recently been found not to be the only role for $\mathrm{ABC}$ transporters in the failure of cancer therapy. They may also release signaling molecules, hormones, and metabolites andregulate cellular redox status, membrane lipid composition and tumor microenvironment. Additionally, MAPK, WNT, VEGF, and p53 and other signaling pathways involved in cell differentiation and proliferation should also be concerned, because they also regulate the expression and membrane localization of $\mathrm{ABC}$ transporters. Conclusively, the clinical failure of the $\mathrm{ABC}$ inhibitors makes it urgent to discover a more effective strategy.

Regarding further research on multidrug resistance, three main aspects could be focused on in future: 1) Develop a more precise drug delivery system, especially target cancer stem cells and other poorly differentiated cells. From the previous studies on cancer and multidrug resistance, we know that $\mathrm{ABC}$ transporters mainly overexpress in poorly differentiated cells and lead to multidrug resistance.

\section{REFERENCES}

Abdallah, H. M., Al-Abd, A. M., El-Dine, R. S., and El-Halawany, A. M. (2015). P-glycoprotein inhibitors of natural origin as potential tumor chemosensitizers: a review. J. Adv. Res. 6 (1), 45-62. doi:10.1016/j.jare.2014.11.008

Abdel Gaber, S. A., Müller, P., Zimmermann, W., Hüttenberger, D., Wittig, R., Abdel Kader, M. H., et al. (2018). ABCG2-mediated suppression of chlorin e6 accumulation and photodynamic therapy efficiency in glioblastoma cell lines can be reversed by KO143. J. Photochem. Photobiol. B. 178, 182-191. doi:10. 1016/j.jphotobiol.2017.10.035

Adamska, A., and Falasca, M. (2018). ATP-binding cassette transporters in progression and clinical outcome of pancreatic cancer: what is the way forward? World J. Gastroenterol. 24 (29), 3222-3238. doi:10.3748/wjg.v24. i29.3222

Ahmed, S., Khan, H., Aschner, M., Mirzae, H., Küpeli Akkol, E., and Capasso, R. (2020). Anticancer potential of furanocoumarins: mechanistic and therapeutic aspects. Int. J. Mol. Sci. 21 (16), 5622. doi:10.3390/ijms21165622

Ahmed-Belkacem, A., Pozza, A., Muñoz-Martínez, F., Bates, S. E., Castanys, S., Gamarro, F., et al. (2005). Flavonoid structure-activity studies identify 6prenylchrysin and tectochrysin as potent and specific inhibitors of breast cancer resistance protein ABCG2. Cancer Res. 65 (11), 4852-4860. doi:10. 1158/0008-5472.Can-04-1817

Alam, A., Kowal, J., Broude, E., Roninson, I., and Locher, K. P. (2019). Structural insight into substrate and inhibitor discrimination by human P-glycoprotein. Science 363 (6428), 753-756. doi:10.1126/science.aav7102

Alam, A., Küng, R., Kowal, J., McLeod, R. A., Tremp, N., Broude, E. V., et al. (2018). Structure of a zosuquidar and UIC2-bound human-mouse chimeric ABCB1. Proc. Natl. Acad. Sci. U.S.A. 115 (9), E1973-e1982. doi:10.1073/pnas.1717044115

Allen, J. D., van Loevezijn, A., Lakhai, J. M., van der Valk, M., van Tellingen, O., Reid, G., et al. (2002). Available at: https://mct.aacrjournals.org/content/1/6/ 417. PMID: 12477054. Potent and specific inhibition of the breast cancer resistance protein multidrug transporter in vitro and in mouse intestine by a novel analogue of fumitremorgin C. Mol. Cancer Ther. 1 (6), 417-425.

Ambjørner, S. E. B., Wiese, M., Köhler, S. C., Svindt, J., Lund, X. L., Gajhede, M., et al. (2020). The pyrazolo[3,4-d]pyrimidine derivative, SCO-201, reverses multidrug resistance mediated by ABCG2/BCRP. Cells 9 (3), 613. doi:10. $3390 /$ cells 9030613
However, when drugs are delivered, they also nonspecifically target the $\mathrm{ABC}$ transporters of normal cells, causing many side effects. Therefore, precise delivery systems are necessary to ensure alleviation of side effects. 2) Find more about the signaling pathways related to $\mathrm{ABC}$ transporters. Researchers have found that signaling pathways like MAPK, WNT, VEGF, and p53 are deeply involved in regulating the expression, location of $\mathrm{ABC}$ transporters. Proper inhibition or activation of these signaling pathways can also reduce multidrug resistance. 3) Further investigate the molecular mechanism of ABC transporters in complex with different substrates in details by using structural biology, which provides insights in drug design and development.

\section{AUTHOR CONTRIBUTIONS}

YZ and LM wrote the manuscript; QS revised the manuscript.

\section{FUNDING}

This work was supported by the National Natural Science Foundation of China (21702141).

Amiri-Kordestani, L., Basseville, A., Kurdziel, K., Fojo, A. T., and Bates, S. E (2012). Targeting MDR in breast and lung cancer: discriminating its potential importance from the failure of drug resistance reversal studies. Drug Resist. Updates 15 (1-2), 50-61. doi:10.1016/j.drup.2012.02.002

Ando, T., Kusuhara, H., Merino, G., Alvarez, A. I., Schinkel, A. H., and Sugiyama, Y. (2007). Involvement of breast cancer resistance protein (ABCG2) in the biliary excretion mechanism of fluoroquinolones. Drug Metab. Dispos. 35 (10), 1873-1879. doi:10.1124/dmd.107.014969

Antoni, F., Bause, M., Scholler, M., Bauer, S., Stark, S. A., Jackson, S. M., et al. (2020). Tariquidar-related triazoles as potent, selective and stable inhibitors of ABCG2 (BCRP). Eur. J. Med. Chem. 191, 112133. doi:10.1016/j.ejmech.2020.112133

Bakos, E., Evers, R., Calenda, G., Tusnády, G. E., Szakács, G., Váradi, A., et al. (2000a). Characterization of the amino-terminal regions in the human multidrug resistance protein (MRP1). J. Cell Sci. 113 Pt 24, 4451-4461. Available at: https://pubmed.ncbi.nlm.nih.gov/11082039/.

Bakos, É., Evers, R., Sinkó, E., Váradi, A., Borst, P., and Sarkadi, B. (2000b). Interactions of the human multidrug resistance proteins MRP1 and MRP2 with organic anions. Mol. Pharmacol. 57 (4), 760-768. doi:10.1124/mol.57.4.760

Bakos, É., Evers, R., Szakács, G., Tusnády, G. E., Welker, E., Szabó, K., et al. (1998). Functional multidrug resistance protein (MRP1) lacking the N-terminal transmembrane domain. J. Biol. Chem. 273 (48), 32167-32175. doi:10.1074/jbc.273.48.32167

Ball, B., Zeidan, A., Gore, S. D., and Prebet, T. (2017). Hypomethylating agent combination strategies in myelodysplastic syndromes: hopes and shortcomings. Leuk. Lymphoma 58 (5), 1022-1036. doi:10.1080/10428194.2016.1228927

Basu, R., Baumgaertel, N., Wu, S., and Kopchick, J. J. (2017). Growth hormone receptor knockdown sensitizes human melanoma cells to chemotherapy by attenuating expression of $\mathrm{ABC}$ drug efflux pumps. Horm. Cancer 8 (3), 143-156. doi:10.1007/s12672-017-0292-7

Bharate, J. B., Singh, S., Wani, A., Sharma, S., Joshi, P., Khan, I. A., et al. (2015). Discovery of 4-acetyl-3-(4-fluorophenyl)-1-(p-tolyl)-5-methylpyrrole as a dual inhibitor of human P-glycoprotein and Staphylococcus aureus Nor A efflux pump. Org. Biomol. Chem. 13 (19), 5424-5431. doi:10.1039/c5ob00246j

Borska, S., Chmielewska, M., Wysocka, T., Drag-Zalesinska, M., Zabel, M., and Dziegiel, P. (2012). In vitro effect of quercetin on human gastric carcinoma: targeting cancer cells death and MDR. Food Chem. Toxicol. 50 (9), 3375-3383. doi:10.1016/j.fct.2012.06.035

Boumendjel, A. n., Di Pietro, A., Dumontet, C., and Barron, D. (2002). Recent advances in the discovery of flavonoids and analogs with high-affinity binding 
to P-glycoprotein responsible for cancer cell multidrug resistance. Med. Res. Rev. 22 (5), 512-529. doi:10.1002/med.10015

Bram, E. E., Adar, Y., Mesika, N., Sabisz, M., Skladanowski, A., and Assaraf, Y. G. (2009a). Structural determinants of imidazoacridinones facilitating antitumor activity are crucial for substrate recognition by ABCG2. Mol. Pharmacol. 75 (5), 1149-1159. doi:10.1124/mol.109.054791

Bram, E. E., Stark, M., Raz, S., and Assaraf, Y. G. (2009b). Chemotherapeutic druginduced ABCG2 promoter demethylation as a novel mechanism of acquired multidrug resistance. Neoplasia 11 (12), 1359-1370. doi:10.1593/neo.91314

Braunová, A., Kaňa, M., Kudláčová, J., Kostka, L., Bouček, J., Betka, J., et al. (2019). Micelle-forming block copolymers tailored for inhibition of P-gp-mediated multidrug resistance: structure to activity relationship. Pharmaceutics 11 (11), 579. doi:10.3390/pharmaceutics 11110579

Bugde, P., Biswas, R., Merien, F., Lu, J., Liu, D.-X., Chen, M., et al. (2017). The therapeutic potential of targeting $\mathrm{ABC}$ transporters to combat multi-drug resistance. Expert Opin. Ther. Targets 21 (5), 511-530. doi:10.1080/ 14728222.2017.1310841

Chanmahasathien, W., Ampasavate, C., Greger, H., and Limtrakul, P. (2011). Stemona alkaloids, from traditional Thai medicine, increase chemosensitivity via P-glycoprotein-mediated multidrug resistance. Phytomedicine 18 (2-3), 199-204. doi:10.1016/j.phymed.2010.07.014

Chapuy, B., Koch, R., Radunski, U., Corsham, S., Cheong, N., Inagaki, N., et al. (2008). Intracellular $\mathrm{ABC}$ transporter $\mathrm{A} 3$ confers multidrug resistance in leukemia cells by lysosomal drug sequestration. Leukemia 22 (8), 1576-1586. doi:10.1038/leu.2008.103

Chen, J. R., Jia, X. H., Wang, H., Yi, Y. J., Wang, J. Y., and Li, Y. J. (2016a). Timosaponin A-III reverses multi-drug resistance in human chronic myelogenous leukemia K562/ADM cells via downregulation of MDR1 and MRP1 expression by inhibiting PI3K/Akt signaling pathway. Int. J. Oncol. 48 (5), 2063-2070. doi:10.3892/ijo.2016.3423

Chen, Y. J., Huang, W. C., Wei, Y. L., Hsu, S. C., Yuan, P., Lin, H. Y., et al. (2011). Elevated BCRP/ABCG2 expression confers acquired resistance to gefitinib in wild-type EGFR-expressing cells. PLoS One 6 (6), e21428. doi:10.1371/journal. pone. 0021428

Chen, Y. Y., Chang, Y. M., Wang, K. Y., Chen, P. N., Hseu, Y. C., Chen, K. M., et al. (2019). Naringenin inhibited migration and invasion of glioblastoma cells through multiple mechanisms. Environ. Toxicol. 34 (3), 233-239. doi:10. 1002/tox.22677

Chen, Y. L., Chen, P. M., Lin, P. Y., Hsiau, Y. T., and Chu, P. Y. (2016b). ABCG2 overexpression confers poor outcomes in hepatocellular carcinoma of elderly patients. Anticancer Res. 36 (6), 2983-2988. Available at: https://pubmed.ncbi. nlm.nih.gov/27272814/.

Chen, Z., Chen, Y., Xu, M., Chen, L., Zhang, X., To, K. K. W., et al. (2016c). Osimertinib (AZD9291) enhanced the efficacy of chemotherapeutic agents in ABCB1- and ABCG2-overexpressing cells in vitro, in vivo, and ex vivo. Mol. Cancer Ther. 15 (8), 1845-1858. doi:10.1158/1535-7163.Mct-15-0939

Christie, E. L., Pattnaik, S., Beach, J., Copeland, A., Rashoo, N., Fereday, S., et al. (2019). Multiple ABCB1 transcriptional fusions in drug resistant high-grade serous ovarian and breast cancer. Nat. Commun. 10 (1), 1295. doi:10.1038/ s41467-019-09312-9

Cihalova, D., Ceckova, M., Kucera, R., Klimes, J., and Staud, F. (2015). Dinaciclib, a cyclin-dependent kinase inhibitor, is a substrate of human ABCB1 and ABCG2 and an inhibitor of human ABCC1 in vitro. Biochem. Pharmacol. 98 (3), 465-472. doi:10.1016/j.bcp.2015.08.099

Cole, S., Bhardwaj, G., Gerlach, J., Mackie, J., Grant, C., Almquist, K., et al. (1992). Overexpression of a transporter gene in a multidrug-resistant human lung cancer cell line. Science 258 (5088), 1650-1654. doi:10.1126/science.1360704

Cole, S. P. C. (2014). Targeting multidrug resistance protein 1 (MRP1,ABCC1): past, present, and future. Annu. Rev. Pharmacol. Toxicol. 54, 95-117. doi:10. 1146/annurev-pharmtox-011613-135959

Conseil, G., Arama-Chayoth, M., Tsfadia, Y., and Cole, S. P. C. (2019). Structureguided probing of the leukotriene C4binding site in human multidrug resistance protein 1 (MRP1; ABCC1). FASEB j. 33 (10), 10692-10704. doi:10.1096/fj.201900140R

Csandl, M. A., Conseil, G., and Cole, S. P. C. (2016). Cysteinyl leukotriene receptor $1 / 2$ antagonists nonselectively modulate organic anion transport by multidrug resistance proteins (MRP1-4). Drug Metab. Dispos. 44 (6), 857-866. doi:10. 1124/dmd.116.069468
Dawson, R. J. P., and Locher, K. P. (2006). Structure of a bacterial multidrug ABC transporter. Nature 443 (7108), 180-185. doi:10.1038/nature05155

Ding, Y., Li, S., Ge, W., Liu, Z., Zhang, X., Wang, M., et al. (2019). Design and synthesis of parthenolide and 5-fluorouracil conjugates as potential anticancer agents against drug resistant hepatocellular carcinoma. Eur. J. Med. Chem. 183, 111706. doi:10.1016/j.ejmech.2019.111706

Dohse, M., Scharenberg, C., Shukla, S., Robey, R. W., Volkmann, T., Deeken, J. F., et al. (2010). Comparison of ATP-binding cassette transporter interactions with the tyrosine kinase inhibitors imatinib, nilotinib, and dasatinib. Drug Metab. Dispos. 38 (8), 1371-1380. doi:10.1124/dmd.109.031302

Drozd, E., Krzysztoń-Russjan, J., Marczewska, J., Drozd, J., Bubko, I., Bielak, M., et al. (2016). Up-regulation of glutathione-related genes, enzyme activities and transport proteins in human cervical cancer cells treated with doxorubicin. Biomed. Pharmacother. 83, 397-406. doi:10.1016/j.biopha.2016.06.051

Dulucq, S., Bouchet, S., Turcq, B., Lippert, E., Etienne, G., Reiffers, J., et al. (2008). Multidrug resistance gene (MDR1) polymorphisms are associated with major molecular responses to standard-dose imatinib in chronic myeloid leukemia. Blood 112 (5), 2024-2027. doi:10.1182/blood-2008-03-147744

Durante, M., Frosini, M., Fusi, F., Neri, A., Sticozzi, C., and Saponara, S. (2017). In vitro vascular toxicity of tariquidar, a potential tool for in vivo PET studies. Toxicol. Vitro 44, 241-247. doi:10.1016/j.tiv.2017.07.015

Dury, L., Nasr, R., Lorendeau, D., Comsa, E., Wong, I., Zhu, X., et al. (2017). Flavonoid dimers are highly potent killers of multidrug resistant cancer cells overexpressing MRP1. Biochem. Pharmacol. 124, 10-18. doi:10.1016/j.bcp. 2016.10.013

Eid, S. Y., El-Readi, M. Z., and Wink, M. (2012). Synergism of three-drug combinations of sanguinarine and other plant secondary metabolites with digitonin and doxorubicin in multi-drug resistant cancer cells. Phytomedicine 19 (14), 1288-1297. doi:10.1016/j.phymed.2012.08.010

Emmanouilidi, A., Casari, I., Gokcen Akkaya, B., Maffucci, T., Furic, L., Guffanti, F., et al. (2020). Inhibition of the lysophosphatidylinositol transporter ABCC1 reduces prostate cancer cell growth and sensitizes to chemotherapy. Cancers 12 (8), 2022. doi:10.3390/cancers 12082022

Falcone Ferreyra, M. L., Rius, S. P., and Casati, P. (2012). Flavonoids: biosynthesis, biological functions, and biotechnological applications. Front. Plant Sci. 3, 222. doi:10.3389/fpls.2012.00222

Fallatah, O., and Georges, E. (2017). Apigenin-induced ABCC1-mediated efflux of glutathione from mature erythrocytes inhibits the proliferation of Plasmodium falciparum. Int. J. Antimicrob. Agents. 50 (5), 673-677. doi:10.1016/j. ijantimicag.2017.08.014

Ferreira, R. J., Baptista, R., Moreno, A., Madeira, P. G., Khonkarn, R., BaubichonCortay, H., et al. (2018). Optimizing the flavanone core toward new selective nitrogen-containing modulators of ABC transporters. Future Med. Chem. 10 (7), 725-741. doi:10.4155/fmc-2017-0228

Fletcher, J. I., Williams, R. T., Henderson, M. J., Norris, M. D., and Haber, M. (2016). ABC transporters as mediators of drug resistance and contributors to cancer cell biology. Drug Resist. Updates 26, 1-9. doi:10.1016/j.drup.2016. 03.001

Fu, P., Kong, F., Li, X., Wang, Y., and Zhu, W. (2014). Cyanogramide with a new spiro[indolinone-pyrroloimidazole] skeleton from Actinoalloteichus cyanogriseus. Org. Lett. 16 (14), 3708-3711. doi:10.1021/ol501523d

Gameiro, M., Silva, R., Rocha-Pereira, C., Carmo, H., Carvalho, F., Bastos, M., et al. (2017). Cellular models and in vitro assays for the screening of modulators of P-gp, MRP1 and BCRP. Molecules 22 (4), 600. doi:10.3390/ molecules 22040600

Gana, C. C., Hanssen, K. M., Yu, D. M. T., Flemming, C. L., Wheatley, M. S., Conseil, G., et al. (2019). MRP1 modulators synergize with buthionine sulfoximine to exploit collateral sensitivity and selectively kill MRP1expressing cancer cells. Biochem. Pharmacol. 168, 237-248. doi:10.1016/j. bcp.2019.07.009

Gao, J., and Aisa, H. A. (2017). Terpenoids from Euphorbia soongarica and their multidrug resistance reversal activity. J. Nat. Prod. 80 (6), 1767-1775. doi:10. 1021/acs.jnatprod.6b01099

Gatlik-Landwojtowicz, E., Äänismaa, P., and Seelig, A. (2006). Quantification and characterization of P-glycoprotein-substrate interactions. Biochemistry 45 (9), 3020-3032. doi:10.1021/bi051380+

Geourjon, C., Orelle, C., Steinfels, E., Blanchet, C., Deléage, G., Di Pietro, A., et al. (2001). A common mechanism for ATP hydrolysis in ABC transporter and 
helicase superfamilies. Trends Biochem. Sci. 26 (9), 539-544. doi:10.1016/s09680004(01)01907-7

Gergely, J. E., Dorsey, A. E., Dimri, G. P., and Dimri, M. (2018). Timosaponin A-III inhibits oncogenic phenotype via regulation of PcG protein BMI1 in breast cancer cells. Mol. Carcinog. 57 (7), 831-841. doi:10.1002/mc.22804

Gewin, L. S., Summers, M. E., Harral, J. W., Gaskill, C. F., Khodo, S. N., Neelisetty, S., et al. (2019). Inactivation of Tsc2 in Abcg2 lineage-derived cells drives the appearance of polycystic lesions and fibrosis in the adult kidney. Am. J. Physiol. Renal. Physiol. 317 (5), F1201-F1210. doi:10.1152/ajprenal.00629.2018

Gonçalves, B. M. F., Cardoso, D. S. P., and Ferreira, M. U. (2020). Overcoming multidrug resistance: flavonoid and terpenoid nitrogen-containing derivatives as ABC transporter modulators. Molecules 25 (15), 3364. doi:10.3390/ molecules 25153364

Gottesman, M. M., Hrycyna, C. A., Schoenlein, P. V., Germann, U. A., and Pastan, I. (1995). Genetic analysis of the multidrug transporter. Annu. Rev. Genet. 29, 607-649. doi:10.1146/annurev.ge.29.120195.003135

Gupta, P., Xie, M., Narayanan, S., Wang, Y. J., Wang, X. Q., Yuan, T., et al. (2017). GSK1904529A, a potent IGF-IR inhibitor, reverses MRP1-mediated multidrug resistance. J. Cell. Biochem. 118 (10), 3260-3267. doi:10.1002/jcb.25975

Halwachs, S., Kneuer, C., Gohlsch, K., Müller, M., Ritz, V., and Honscha, W. (2016). The ABCG2 efflux transporter from rabbit placenta: cloning and functional characterization. Placenta 38, 8-15. doi:10.1016/j.placenta.2015. 12.005

Hegedüs, C., Truta-Feles, K., Antalffy, G., Várady, G., Német, K., Özvegy-Laczka, C., et al. (2012). Interaction of the EGFR inhibitors gefitinib, vandetanib, pelitinib and neratinib with the ABCG2 multidrug transporter: implications for the emergence and reversal of cancer drug resistance. Biochem. Pharmacol. 84 (3), 260-267. doi:10.1016/j.bcp.2012.04.010

Henderson, M. J., Haber, M., Porro, A., Munoz, M. A., Iraci, N., Xue, C., et al. (2011). ABCC multidrug transporters in childhood neuroblastoma: clinical and biological effects independent of cytotoxic drug efflux. J. Natl. Cancer Inst. 103 (16), 1236-1251. doi:10.1093/jnci/djr256

Henrich, C. J., Bokesch, H. R., Dean, M., Bates, S. E., Robey, R. W., Goncharova, E. I., et al. (2006). A high-throughput cell-based assay for inhibitors of ABCG2 activity. J. Biomol. Screen. 11 (2), 176-183. doi:10.1177/1087057105284576

Huang, H. Y., Niu, J. L., and Lu, Y. H. (2012). Multidrug resistance reversal effect of DMC derived from buds of Cleistocalyx operculatus in human hepatocellular tumor xenograft model. J. Sci. Food Agric. 92 (1), 135-140. doi:10.1002/jsfa. 4551

Huang, L., Hu, C., Benedetto, M. D., Di Benedetto, M., Liu, J., Jin, J., et al. (2015). Cross-drug resistance to sunitinib induced by doxorubicin in endothelial cells. Oncol. Lett. 9 (3), 1287-1292. doi:10.3892/ol.2014.2819

Huang, X. C., Xiao, X., Zhang, Y. K., Talele, T., Salim, A., Chen, Z. S., et al. (2014). Lamellarin $\mathrm{O}$, a pyrrole alkaloid from an Australian marine sponge, Ianthella sp., reverses BCRP mediated drug resistance in cancer cells. Mar. Drugs 12 (7), 3818-3837. doi:10.3390/md12073818

Huang, Y., Dai, Y., Wen, C., He, S., Shi, J., Zhao, D., et al. (2020). circSETD3 contributes to acquired resistance to gefitinib in non-small-cell lung cancer by targeting the miR-520h/ABCG2 pathway. Mol. Ther. - Nucleic Acids 21, 885-899. doi:10.1016/j.omtn.2020.07.027

Ishikawa, T., Aw, W., and Kaneko, K. (2013). Metabolic interactions of purine derivatives with human $\mathrm{ABC}$ transporter $\mathrm{ABCG} 2$ : genetic testing to assess gout risk. Pharmaceuticals 6 (11), 1347-1360. doi:10.3390/ph6111347

Jackson, S. M., Manolaridis, I., Kowal, J., Zechner, M., Taylor, N. M. I., Bause, M., et al. (2018). Structural basis of small-molecule inhibition of human multidrug transporter ABCG2. Nat. Struct. Mol. Biol. 25 (4), 333-340. doi:10.1038/ s41594-018-0049-1

Jain, S., Laphookhieo, S., Shi, Z., Fu, L. W., Akiyama, S. I., Chen, Z. S., et al. (2007). Reversal of P-glycoprotein-mediated multidrug resistance by sipholane triterpenoids. J. Nat. Prod. 70 (6), 928-931. doi:10.1021/np0605889

Ji, L., Liu, X., Zhang, S., Tang, S., Yang, S., Li, S., et al. (2017). The novel triazolonaphthalimide derivative LSS-11 synergizes the anti-proliferative effect of paclitaxel via STAT3-dependent MDR1 and MRP1 downregulation in chemoresistant lung cancer cells. Molecules 22 (11), 1822. doi:10.3390/ molecules 22111822

Jiang, M., Zhang, R., Wang, Y., Jing, W., Liu, Y., Ma, Y., et al. (2017). Reduction-sensitive paclitaxel prodrug self-assembled nanoparticles with tetrandrine effectively promote synergistic therapy against drug-sensitive and multidrug-resistant breast cancer. Mol. Pharm. 14 (11), 3628-3635. doi:10.1021/acs.molpharmaceut.7b00381

Johnson, Z. L., and Chen, J. (2017). Structural basis of substrate recognition by the multidrug resistance protein MRP1. Cell 168 (6), 1075-1085.e9. doi:10.1016/j. cell.2017.01.041

Jordanides, N. E., Jorgensen, H. G., Holyoake, T. L., and Mountford, J. C. (2006), Functional ABCG2 is overexpressed on primary CML CD34+ cells and is inhibited by imatinib mesylate. Blood 108 (4), 1370-1373. doi:10.1182/blood2006-02-003145

Juliano, R. L., and Ling, V. (1976). A surface glycoprotein modulating drug permeability in Chinese hamster ovary cell mutants. Biochim. Biophys. Acta 455 (1), 152-162. doi:10.1016/0005-2736(76)90160-7

Kashiwayama, Y., Seki, M., Yasui, A., Murasaki, Y., Morita, M., Yamashita, Y., et al. (2009). 70-kDa peroxisomal membrane protein related protein (P70R/ABCD4) localizes to endoplasmic reticulum not peroxisomes, and $\mathrm{NH} 2$-terminal hydrophobic property determines the subcellular localization of $\mathrm{ABC}$ subfamily D proteins. Exp. Cell. Res. 315 (2), 190-205. doi:10.1016/j.yexcr. 2008.10.031

Kathawala, R. J., Gupta, P., Ashby, C. R., Jr., and Chen, Z.-S. (2015). The modulation of $\mathrm{ABC}$ transporter-mediated multidrug resistance in cancer: a review of the past decade. Drug Resist. Updates 18, 1-17. doi:10.1016/j.drup. 2014.11.002

Khunweeraphong, N., Stockner, T., and Kuchler, K. (2017). The structure of the human $\mathrm{ABC}$ transporter ABCG2 reveals a novel mechanism for drug extrusion. Sci. Rep. 7 (1), 13767. doi:10.1038/s41598-017-11794-w

Khunweeraphong, N., Szöllösi, D., Stockner, T., and Kuchler, K. (2019). The ABCG2 multidrug transporter is a pump gated by a valve and an extracellular lid. Nat. Commun. 10 (1), 5433. doi:10.1038/s41467-019-13302-2

Kim, Y., and Chen, J. (2018). Molecular structure of human P-glycoprotein in the ATP-bound, outward-facing conformation. Science 359 (6378), 915-919. doi:10.1126/science.aar7389

Kraege, S., Köhler, S. C., and Wiese, M. (2016a). Acryloylphenylcarboxamides: a new class of breast cancer resistance protein (ABCG2) modulators. ChemMedChem 11 (21), 2422-2435. doi:10.1002/cmdc.201600341

Kraege, S., Stefan, K., Juvale, K., Ross, T., Willmes, T., and Wiese, M. (2016b). The combination of quinazoline and chalcone moieties leads to novel potent heterodimeric modulators of breast cancer resistance protein (BCRP/ ABCG2). Eur. J. Med. Chem. 117, 212-229. doi:10.1016/j.ejmech.2016.03.067

Kraege, S., Stefan, K., Köhler, S. C., and Wiese, M. (2016c). Optimization of acryloylphenylcarboxamides as inhibitors of ABCG2 and comparison with acryloylphenylcarboxylates. ChemMedChem 11 (22), 2547-2558. doi:10.1002/ cmdc. 201600455

Kumar, A., and Jaitak, V. (2019). Natural products as multidrug resistance modulators in cancer. Eur. J. Med. Chem. 176, 268-291. doi:10.1016/j. ejmech.2019.05.027

Lainey, E., Sébert, M., Thépot, S., Scoazec, M., Bouteloup, C., Leroy, C., et al. (2012). Erlotinib antagonizes ABC transporters in acute myeloid leukemia. Cell Cycle 11 (21), 4079-4092. doi:10.4161/cc.22382

Lainey, E., Wolfromm, A., Marie, N., Enot, D., Scoazec, M., Bouteloup, C., et al. (2013). Azacytidine and erlotinib exert synergistic effects against acute myeloid leukemia. Oncogene 32 (37), 4331-4342. doi:10.1038/onc.2012.469

Leier, I., Jedlitschky, G., Buchholz, U., Cole, S. P., Deeley, R. G., and Keppler, D. (1994). The MRP gene encodes an ATP-dependent export pump for leukotriene C4 and structurally related conjugates. J. Biol. Chem. 269 (45), 27807-27810. doi:10.1016/s0021-9258(18)46856-1

Li, C., Zou, J., Zheng, G., and Chu, J. (2016). MiR-30a decreases multidrug resistance (MDR) of gastric cancer cells. Med. Sci. Monit. 22, 4505-4515. doi:10.12659/msm.898415

Li, Y., Liu, Y., Ren, J., Deng, S., Yi, G., Guo, M., et al. (2018). miR-1268a regulates $\mathrm{ABCC} 1$ expression to mediate temozolomide resistance in glioblastoma. J. Neurooncol. 138 (3), 499-508. doi:10.1007/s11060-018-2835-3

Li, Y., Zhai, Z., Li, H., Wang, X., Huang, Y., and Su, X. (2019). Guajadial reverses multidrug resistance by inhibiting $\mathrm{ABC}$ transporter expression and suppressing the PI3K/Akt pathway in drug-resistant breast cancer cells. Chemico-Biol. Interact 305, 98-104. doi:10.1016/j.cbi.2019.03.032

Li, Y., Zhao, L., Li, N., Miao, Y., Zhou, H., and Jia, L. (2017). miR-9 regulates the multidrug resistance of chronic myelogenous leukemia by targeting ABCB1. Oncol. Rep. 37 (4), 2193-2200. doi:10.3892/or.2017.5464 
Liang, Z., Wu, H., Xia, J., Li, Y., Zhang, Y., Huang, K., et al. (2010). Involvement of miR-326 in chemotherapy resistance of breast cancer through modulating expression of multidrug resistance-associated protein 1. Biochem. Pharmacol. 79 (6), 817-824. doi:10.1016/j.bcp.2009.10.017

Liening, S., Scriba, G. K., Rummler, S., Weinigel, C., Kleinschmidt, T. K., Haeggström, J. Z., et al. (2016). Development of smart cell-free and cellbased assay systems for investigation of leukotriene C 4 synthase activity and evaluation of inhibitors. Biochim. Biophys. Acta 1861 (11), 1605-1613. doi:10.1016/j.bbalip.2016.07.011

Liu, X. L., Tee, H. W., and Go, M. L. (2008). Functionalized chalcones as selective inhibitors of P-glycoprotein and breast cancer resistance protein. Bioorg. Med. Chem. 16 (1), 171-180. doi:10.1016/j.bmc.2007.10.006

Locher, K. P., Lee, A. T., and Rees, D. C. (2002). The E. coli BtuCD structure: a framework for ABC transporter architecture and mechanism. Science 296 (5570), 1091-1098. doi:10.1126/science.1071142

Loe, D. W., Almquist, K. C., Deeley, R. G., and Cole, S. P. C. (1996). Multidrug resistance protein (MRP)-mediated transport of leukotriene $\mathrm{C} 4$ and chemotherapeutic agents in membrane vesicles. J. Biol. Chem. 271 (16), 9675-9682. doi:10.1074/jbc.271.16.9675

Lorendeau, D., Dury, L., Genoux-Bastide, E., Lecerf-Schmidt, F., Simões-Pires, C., Carrupt, P. A., et al. (2014). Collateral sensitivity of resistant MRP1overexpressing cells to flavonoids and derivatives through GSH efflux. Biochem. Pharmacol. 90 (3), 235-245. doi:10.1016/j.bcp.2014.05.017

Lu, C., Shan, Z., Li, C., and Yang, L. (2017). MiR-129 regulates cisplatin-resistance in human gastric cancer cells by targeting P-gp. Biomed. Pharmacother. 86, 450-456. doi:10.1016/j.biopha.2016.11.139

Manayi, A., Nabavi, S. M., Setzer, W. N., and Jafari, S. (2019). Piperine as a potential anti-cancer agent: a review on preclinical studies. Curr Med Chem. 25 (37), 4918-4928. doi:10.2174/0929867324666170523120656

Manolaridis, I., Jackson, S. M., Taylor, N. M. I., Kowal, J., Stahlberg, H., and Locher, K. P. (2018). Cryo-EM structures of a human ABCG2 mutant trapped in ATPbound and substrate-bound states. Nature 563 (7731), 426-430. doi:10.1038/ s41586-018-0680-3

Mao, Q., and Unadkat, J. D. (2015). Role of the breast cancer resistance protein (BCRP/ABCG2) in drug transport-an update. Aaps J. 17 (1), 65-82. doi:10. 1208/s12248-014-9668-6

Mares, L., Vilchis, F., Chávez, B., and Ramos, L. (2019). Expression and regulation of ABCG2/BCRP1 by sex steroids in the Harderian gland of the Syrian hamster (Mesocricetus auratus). C. R. Biol. 342 (9-10), 279-289. doi:10.1016/j.crvi.2019. 11.003

Matei, D., Fang, F., Shen, C., Schilder, J., Arnold, A., Zeng, Y., et al. (2012). Epigenetic resensitization to platinum in ovarian cancer. Cancer Res. 72 (9), 2197-2205. doi:10.1158/0008-5472.Can-11-3909

Mesraoua, B., Deleu, D., Kullmann, D. M., Shetty, A. K., Boon, P., Perucca, E., et al. (2019). Novel therapies for epilepsy in the pipeline. Epilepsy Behav. 97, 282-290. doi:10.1016/j.yebeh.2019.04.042

Moody, J. E., Millen, L., Binns, D., Hunt, J. F., and Thomas, P. J. (2002). Cooperative, ATP-dependent association of the nucleotide binding cassettes during the catalytic cycle of ATP-binding cassette transporters. J. Biol. Chem. 277 (24), 21111-21114. doi:10.1074/jbc.C200228200

Munagala, S., Sirasani, G., Kokkonda, P., Phadke, M., Krynetskaia, N., Lu, P., et al. (2014). Synthesis and evaluation of Strychnos alkaloids as MDR reversal agents for cancer cell eradication. Bioorg. Med. Chem. 22 (3), 1148-1155. doi:10.1016/j. bmc.2013.12.022

Nabekura, T., Yamaki, T., and Kitagawa, S. (2008). Effects of chemopreventive citrus phytochemicals on human P-glycoprotein and multidrug resistance protein 1. Eur. J. Pharmacol. 600 (1-3), 45-49. doi:10.1016/j.ejphar.2008.10.025

Nasr, R., Lorendeau, D., Khonkarn, R., Dury, L., Pérès, B., Boumendjel, A., et al. (2020). Molecular analysis of the massive GSH transport mechanism mediated by the human Multidrug Resistant Protein 1/ABCC1. Sci. Rep. 10 (1), 7616. doi:10.1038/s41598-020-64400-X

Natarajan, K., Xie, Y., Baer, M. R., and Ross, D. D. (2012). Role of breast cancer resistance protein (BCRP/ABCG2) in cancer drug resistance. Biochem. Pharmacol. 83 (8), 1084-1103. doi:10.1016/j.bcp.2012.01.002

Ni, K., Yang, L., Wan, C., Xia, Y., and Kong, L. (2014). Flavonostilbenes from Sophora alopecuroides L. as multidrug resistance associated protein 1 (MRP1) inhibitors. Nat. Product. Res. 28 (23), 2195-2198. doi:10.1080/14786419.2014. 930856
Nobili, S., Landini, I., Giglioni, B., and Mini, E. (2006). Pharmacological strategies for overcoming multidrug resistance. Cdt 7 (7), 861-879. doi:10.2174/ 138945006777709593

Obreque-Balboa, J. E., Sun, Q., Bernhardt, G., König, B., and Buschauer, A. (2016). Flavonoid derivatives as selective ABCC1 modulators: synthesis and functional characterization. Eur. J. Med. Chem. 109, 124-133. doi:10.1016/j.ejmech.2015. 12.010

Oda, Y., Saito, T., Tateishi, N., Ohishi, Y., Tamiya, S., Yamamoto, H., et al. (2005). ATP-binding cassette superfamily transporter gene expression in human soft tissue sarcomas. Int. J. Cancer 114 (6), 854-862. doi:10.1002/ijc.20589

Ohtsuki, S., Kamoi, M., Watanabe, Y., Suzuki, H., Hori, S., and Terasaki, A. (2007). Correlation of induction of ATP binding cassette transporter A5 (ABCA5) and ABCB1 mRNAs with differentiation state of human colon tumor. Biol. Pharm. Bull. 30 (6), 1144-1146. doi:10.1248/bpb.30.1144

Olarte Carrillo, I., Ramos Peñafiel, C., Miranda Peralta, E., Rozen Fuller, E., Kassack Ipiña, J. J., Centeno Cruz, F., et al. (2017). Clinical significance of the $\mathrm{ABCB} 1$ and $\mathrm{ABCG} 2$ gene expression levels in acute lymphoblastic leukemia. Hematology 22 (5), 286-291. doi:10.1080/10245332.2016.1265780

Oldham, M. L., and Chen, J. (2011). Snapshots of the maltose transporter during ATP hydrolysis. Proc. Natl. Acad. Sci. U.S.A. 108 (37), 15152-15156. doi:10. 1073/pnas. 1108858108

Orlando, B. J., and Liao, M. (2020). ABCG2 transports anticancer drugs via a closed-to-open switch. Nat. Commun. 11 (1), 2264. doi:10.1038/s41467-02016155-2

Orlando, U. D., Castillo, A. F., Medrano, M. A. R., Solano, A. R., Maloberti, P. M., and Podesta, E. J. (2019). Acyl-CoA synthetase-4 is implicated in drug resistance in breast cancer cell lines involving the regulation of energydependent transporter expression. Biochem. Pharmacol. 159, 52-63. doi:10. 1016/j.bcp.2018.11.005

Özvegy-Laczka, C., Hegedüs, T., Várady, G., Ujhelly, O., Schuetz, J. D., Váradi, A., et al. (2004). High-affinity interaction of tyrosine kinase inhibitors with the ABCG2 multidrug transporter. Mol. Pharmacol. 65 (6), 1485-1495. doi:10. 1124/mol.65.6.1485

Parcej, D., and Tampé, R. (2010). ABC proteins in antigen translocation and viral inhibition. Nat. Chem. Biol. 6 (8), 572-580. doi:10.1038/nchembio.410

Pires, M. M., Emmert, D., Hrycyna, C. A., and Chmielewski, J. (2009). Inhibition of P-glycoprotein-mediated paclitaxel resistance by reversibly linked quinine homodimers. Mol. Pharmacol. 75 (1), 92-100. doi:10.1124/mol.108.050492

Porcelli, L., Giovannetti, E., Assaraf, Y., Jansen, G., Scheffer, G., Kathman, I., et al. (2014). The EGFR pathway regulates BCRP expression in NSCLC cells: role of erlotinib. Curr. Drug Targets 15 (14), 1322-1330. doi:10.2174/ 1389450116666141205145620

Porro, A., Haber, M., Diolaiti, D., Iraci, N., Henderson, M., Gherardi, S., et al. (2010). Direct and coordinate regulation of ATP-binding cassette transporter genes by myc factors generates specific transcription signatures that significantly affect the chemoresistance phenotype of cancer cells*. J. Biol. Chem. 285 (25), 19532-19543. doi:10.1074/jbc.M109.078584

Qiu, S., Sun, H., Zhang, A. H., Xu, H. Y., Yan, G. L., Han, Y., et al. (2014). Natural alkaloids: basic aspects, biological roles, and future perspectives. Chin. J. Nat. Med. 12 (6), 401-406. doi:10.1016/s1875-5364(14)60063-7

Raaijmakers, M. H. G. P., de Grouw, E. P. L. M., Heuver, L. H. H., van der Reijden, B. A., Jansen, J. H., Scheper, R. J., et al. (2005). Breast cancer resistance protein in drug resistance of primitive CD34+38- cells in acute myeloid leukemia. Clin. Cancer Res. 11 (6), 2436-2444. doi:10.1158/1078-0432.Ccr-04-0212

Ramalhete, C., Mulhovo, S., Lage, H., and Ferreira, M. J. (2018). Triterpenoids from Momordica balsamina with a collateral sensitivity effect for tackling multidrug resistance in cancer cells. Planta Med. 84 (18), 1372-1379. doi:10.1055/a-06518141

Ramalhete, C., Mulhovo, S., Molnar, J., and Ferreira, M. J. U. (2016). Triterpenoids from Momordica balsamina: reversal of ABCB1-mediated multidrug resistance. Bioorg. Med. Chem. 24 (21), 5061-5067. doi:10.1016/j.bmc.2016.08.022

Reustle, A., Fisel, P., Renner, O., Büttner, F., Winter, S., Rausch, S., et al. (2018). Characterization of the breast cancer resistance protein (BCRP/ABCG2 ) in clear cell renal cell carcinoma. Int. J. Cancer 143 (12), 3181-3193. doi:10.1002/ ijc. 31741

Robey, R. W., Massey, P. R., Amiri-Kordestani, L., and Bates, S. E. (2010). ABC transporters: unvalidated therapeutic targets in cancer and the CNS. Anticancer Agents Med. Chem. 10 (8), 625-633. doi:10.2174/187152010794473957 
Robey, R. W., Pluchino, K. M., Hall, M. D., Fojo, A. T., Bates, S. E., and Gottesman, M. M. (2018). Revisiting the role of ABC transporters in multidrug-resistant cancer. Nat. Rev. Cancer 18 (7), 452-464. doi:10.1038/s41568-018-0005-8

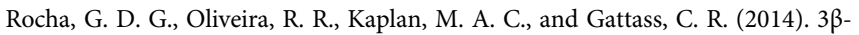
Acetyl tormentic acid reverts MRP1/ABCC1 mediated cancer resistance through modulation of intracellular levels of GSH and inhibition of GST activity. Eur. J. Pharmacol. 741, 140-149. doi:10.1016/j.ejphar.2014.07.054

Sacha, T., and Saglio, G. (2019). Nilotinib in the treatment of chronic myeloid leukemia. Future Oncol. 15 (9), 953-965. doi:10.2217/fon-2018-0468

Sato, H., Siddig, S., Uzu, M., Suzuki, S., Nomura, Y., Kashiba, T., et al. (2015). Elacridar enhances the cytotoxic effects of sunitinib and prevents multidrug resistance in renal carcinoma cells. Eur. J. Pharmacol. 746, 258-266. doi:10. 1016/j.ejphar.2014.11.021

Schinkel, A. H., Smit, J. J. M., van Tellingen, O., Beijnen, J. H., Wagenaar, E., van Deemter, L., et al. (1994). Disruption of the mouse mdrla P-glycoprotein gene leads to a deficiency in the blood-brain barrier and to increased sensitivity to drugs. Cell 77 (4), 491-502. doi:10.1016/0092-8674(94)90212-7

Schmitt, S. M., Stefan, K., and Wiese, M. (2016). Pyrrolopyrimidine derivatives as novel inhibitors of multidrug resistance-associated protein 1 (MRP1, ABCC1). J. Med. Chem. 59 (7), 3018-3033. doi:10.1021/acs.jmedchem.5b01644

Shapiro, A. B., and Ling, V. (1997). Effect of quercetin on Hoechst 33342 transport by purified and reconstituted P-glycoprotein. Biochem. Pharmacol. 53 (4), 587-596. doi:10.1016/s0006-2952(96)00826-x

Sharom, F.J. (2011). The P-glycoprotein multidrug transporter. Essays Biochem. 50 (1), 161-178. doi:10.1042/bse0500161

Sharma, A., Vatapalli, R., Abdelfatah, E., Wyatt McMahon, K., Kerner, Z., Guzzetta, A. A., et al. (2017). Hypomethylating agents synergize with irinotecan to improve response to chemotherapy in colorectal cancer cells. PLoS One 12 (4), e0176139. doi:10.1371/journal.pone.0176139

Shi, Z., Jain, S., Kim, I. W., Peng, X. X., Abraham, I., Youssef, D. T. A., et al. (2007). Sipholenol A, a marine-derived sipholane triterpene, potently reverses P-glycoprotein (ABCB1)-mediated multidrug resistance in cancer cells. Cancer Sci. 98 (9), 1373-1380. doi:10.1111/j.1349-7006.2007.00554.x

Si, X., Gao, Z., Xu, F., and Zheng, Y. (2020). SOX2 upregulates side population cells and enhances their chemoresistant ability by transactivating $\mathrm{ABCC} 1$ expression contributing to intrinsic resistance to paclitaxel in melanoma. Mol. Carcinog. 59 (3), 257-264. doi:10.1002/mc.23148

Silbermann, K., Shah, C. P., Sahu, N. U., Juvale, K., Stefan, S. M., Kharkar, P. S., et al. (2019). Novel chalcone and flavone derivatives as selective and dual inhibitors of the transport proteins ABCB1 and ABCG2. Eur. J. Med. Chem. 164, 193-213. doi:10.1016/j.ejmech.2018.12.019

Sims, J. T., Ganguly, S. S., Bennett, H., Friend, J. W., Tepe, J., and Plattner, R. (2013). Imatinib reverses doxorubicin resistance by affecting activation of STAT3-dependent NF- $\mathrm{kB}$ and HSP27/p38/AKT pathways and by inhibiting ABCB1. PLoS One 8 (1), e55509. doi:10.1371/journal.pone.0055509

Singh, D. V., Godbole, M. M., and Misra, K. (2013). A plausible explanation for enhanced bioavailability of P-gp substrates in presence of piperine: simulation for next generation of P-gp inhibitors. J. Mol. Model 19 (1), 227-238. doi:10. 1007/s00894-012-1535-8

Sita, G., Hrelia, P., Tarozzi, A., and Morroni, F. (2017). P-glycoprotein (ABCB1) and oxidative stress: focus on alzheimer's disease. Oxidative Med. Cell Longevity 2017, 1. doi:10.1155/2017/7905486

Stefan, K., Schmitt, S. M., and Wiese, M. (2017). 9-deazapurines as broad-spectrum inhibitors of the $\mathrm{ABC}$ transport proteins $\mathrm{P}$-glycoprotein, multidrug resistanceassociated protein 1, and breast cancer resistance protein. J. Med. Chem. 60 (21), 8758-8780. doi:10.1021/acs.jmedchem.7b00788

Sultan, M., Vidovic, D., Paine, A. S., Huynh, T. T., Coyle, K. M., Thomas, M. L., et al. (2018). Epigenetic silencing of TAP1 in Aldefluor+Breast cancer stem cells contributes to their enhanced immune evasion. Stem Cells 36 (5), 641-654. doi:10.1002/stem.2780

Sun, L., Chen, W., Qu, L., Wu, J., and Si, J. (2013). Icaritin reverses multidrug resistance of HepG2/ADR human hepatoma cells via downregulation of MDR1 and P-glycoprotein expression. Mol. Med. Rep. 8 (6), 1883-1887. doi:10.3892/ mmr.2013.1742

Surya Sandeep, M., Sridhar, V., Puneeth, Y., Ravindra Babu, P., and Naveen Babu, K. (2014). Enhanced oral bioavailability of felodipine by naringenin in Wistar rats and inhibition of P-glycoprotein in everted rat gut sacsin vitro. Drug Develop. Ind. Pharm. 40 (10), 1371-1377. doi:10.3109/03639045.2013.819885
Syed, S. B., Arya, H., Fu, I. H., Yeh, T. K., Periyasamy, L., Hsieh, H. P., et al. (2017). Targeting P-glycoprotein: investigation of piperine analogs for overcoming drug resistance in cancer. Sci. Rep. 7 (1), 7972. doi:10.1038/s41598-017-08062-2

Takada, T., Yamamoto, T., Matsuo, H., Tan, J. K., Ooyama, K., Sakiyama, M., et al. (2018). Identification of ABCG2 as an exporter of uremic toxin indoxyl sulfate in mice and as a crucial factor influencing CKD progression. Sci. Rep. 8 (1), 11147. doi:10.1038/s41598-018-29208-w

Taylor, N. M. I., Manolaridis, I., Jackson, S. M., Kowal, J., Stahlberg, H., and Locher, K. P. (2017). Structure of the human multidrug transporter ABCG2. Nature 546 (7659), 504-509. doi:10.1038/nature22345

Teodori, E., Dei, S., Bartolucci, G., Perrone, M. G., Manetti, D., Romanelli, M. N., et al. (2017). Structure-activity relationship studies on 6,7-Dimethoxy-2phenethyl-1,2,3,4-tetrahydroisoquinoline derivatives as multidrug resistance reversers. ChemMedChem 12 (16), 1369-1379. doi:10.1002/cmdc.201700239

Tian, J., Xu, Y. Y., Li, L., and Hao, Q. (2017). MiR-490-3p sensitizes ovarian cancer cells to cisplatin by directly targeting ABCC2. Am. J. Transl. Res. 9 (3), 1127-1138.

Toyoda, Y., Takada, T., and Suzuki, H. (2019). Inhibitors of human ABCG2: from technical background to recent updates with clinical implications. Front. Pharmacol. 10, 208. doi:10.3389/fphar.2019.00208

Traxl, A., Mairinger, S., Filip, T., Sauberer, M., Stanek, J., Poschner, S., et al. (2019). Inhibition of $\mathrm{ABCB} 1$ and $\mathrm{ABCG} 2$ at the mouse blood-brain barrier with marketed drugs to improve brain delivery of the model ABCB1/ABCG2 substrate [11C]erlotinib. Mol. Pharm. 16 (3), 1282-1293. doi:10.1021/acs. molpharmaceut.8b01217

Tsuchida, M., Emi, Y., Kida, Y., and Sakaguchi, M. (2008). Human ABC transporter isoform $\mathrm{B} 6$ (ABCB6) localizes primarily in the Golgi apparatus. Biochem. Biophys. Res. Commun. 369 (2), 369-375. doi:10.1016/j.bbrc.2008. 02.027

Uhlén, M., Fagerberg, L., Hallström, B. M., Lindskog, C., Oksvold, P., Mardinoglu, A., et al. (2015). Tissue-based map of the human proteome. Science 347 (6220), 1260419. doi:10.1126/science. 1260419

Vahedi, S., Chufan, E. E., and Ambudkar, S. V. (2017). Global alteration of the drug-binding pocket of human P-glycoprotein (ABCB1) by substitution of fifteen conserved residues reveals a negative correlation between substrate size and transport efficiency. Biochem. Pharmacol. 143, 53-64. doi:10.1016/j.bcp. 2017.07.014

Waghray, D., and Zhang, Q. (2018). Inhibit or evade multidrug resistance P-glycoprotein in cancer treatment. J. Med. Chem. 61 (12), 5108-5121. doi:10.1021/acs.jmedchem.7b01457

Wang, F., Miao, M. X., Sun, B. B., Wang, Z. J., Tang, X. G., Chen, Y., et al. (2017). Acute liver failure enhances oral plasma exposure of zidovudine in rats by downregulation of hepatic UGT2B7 and intestinal P-gp. Acta Pharmacol. Sin. 38 (11), 1554-1565. doi:10.1038/aps.2017.54

Wang, H., Chen, X., Li, T., Xu, J., and Ma, Y. (2016). A myrsinol diterpene isolated from a traditional herbal medicine, LANGDU reverses multidrug resistance in breast cancer cells. J. Ethnopharmacol. 194, 1-5. doi:10.1016/j.jep.2016.08.041

Wang, L., and Sun, Y. (2020). Efflux mechanism and pathway of verapamil pumping by human P-glycoprotein. Arch. Biochem. Biophys. 696, 108675. doi:10.1016/j.abb.2020.108675

Wang, M., Ye, C., Liu, M., Wu, Z., Li, L., Wang, C., et al. (2015a). Synthesis and antitumor activity of 5-(5-halogenated-2-oxo-1H-pyrrolo[2,3-b]pyridin-(3Z)ylidenemethyl)-2,4-dimethyl-1H-pyrrole-3-carboxamides. Bioorg. Med. Chem. Lett. 25 (14), 2782-2787. doi:10.1016/j.bmcl.2015.05.017

Wang, S. Q., Liu, S. T., Zhao, B. X., Yang, F. H., Wang, Y. T., Liang, Q. Y., et al. (2015b). Afatinib reverses multidrug resistance in ovarian cancer via dually inhibiting ATP binding cassette subfamily B member 1. Oncotarget 6 (28), 26142-26160. doi:10.18632/oncotarget.4536

Wei, D. D., Wang, J. S., and Kong, L. Y. (2012). Reversal effects of components from the fruits of Illicium simonsii on human Adriamycin-resistant MCF-7 and 5-fluorouracil-resistant Bel7402 cells. Phytother. Res. 26 (4), 562-567. doi:10. $1002 /$ ptr.3599

Wei, Y. L., Xu, L., Liang, Y., Xu, X. H., and Zhao, X. Y. (2009). Berbamine exhibits potent antitumor effects on imatinib-resistant CML cells in vitro and in vivo. Acta Pharmacol. Sin 30 (4), 451-457. doi:10.1038/aps.2009.19

Weidner, L. D., Zoghbi, S. S., Lu, S., Shukla, S., Ambudkar, S. V., Pike, V. W., et al. (2015). The inhibitor Ko143 is not specific for ABCG2. J. Pharmacol. Exp. Ther. 354 (3), 384-393. doi:10.1124/jpet.115.225482 
Weigl, K. E., Conseil, G., Rothnie, A. J., Arama, M., Tsfadia, Y., and Cole, S. P. C. (2018). An outward-facing aromatic amino acid is crucial for signaling between the membrane-spanning and nucleotide-binding domains of multidrug resistance protein 1 (MRP1; ABCC1). Mol. Pharmacol. 94 (3), 1069-1078. doi:10.1124/mol.118.112615

Weiss, W. A., Aldape, K., Mohapatra, G., Feuerstein, B. G., and Bishop, J. M. (1997). Targeted expression of MYCN causes neuroblastoma in transgenic mice. Embo J. 16 (11), 2985-2995. doi:10.1093/emboj/16.11.2985

Wetering, K., and Sapthu, S. (2012). ABCG2 functions as a general phytoestrogen sulfate transporter in vivo. FASEB J. 26 (10), 4014-4024. doi:10.1096/fj.12210039

Whitt, J. D., Keeton, A. B., Gary, B. D., Sklar, L. A., Sodani, K., Chen, Z. S., et al. (2016). Sulindac sulfide selectively increases sensitivity of ABCC1 expressing tumor cells to doxorubicin and glutathione depletion. J. Biomed. Res. 30 (2), 120-133. doi:10.7555/jbr.30.20150108

Winter, E., Gozzi, G. J., Chiaradia-Delatorre, L. D., Daflon-Yunes, N., Terreux, R., Gauthier, C., et al. (2014). Quinoxaline-substituted chalcones as new inhibitors of breast cancer resistance protein ABCG2: polyspecificity at B-ring position. Drug Des. Devel Ther. 8, 609-619. doi:10.2147/dddt.S56625

Wong, I. L. K., Wang, B. C., Yuan, J., Duan, L.-X., Liu, Z., Liu, T., et al. (2015). Potent and nontoxic chemosensitizer of P-glycoprotein-mediated multidrug resistance in cancer: synthesis and evaluation of methylated epigallocatechin, gallocatechin, and dihydromyricetin derivatives. J. Med. Chem. 58 (11), 4529-4549. doi:10.1021/acs.jmedchem.5b00085

Woo, J.-S., Zeltina, A., Goetz, B. A., and Locher, K. P. (2012). X-ray structure of the Yersinia pestis heme transporter HmuUV. Nat. Struct. Mol. Biol. 19 (12), 1310-1315. doi: $10.1038 / \mathrm{nsmb} .2417$

Yin, H., Dong, J., Cai, Y., Shi, X., Wang, H., Liu, G., et al. (2019). Design, synthesis and biological evaluation of chalcones as reversers of P-glycoprotein-mediated multidrug resistance. Eur. J. Med. Chem. 180, 350-366. doi:10.1016/j.ejmech. 2019.05.053

Yu, J., Zhou, P., Asenso, J., Yang, X.-D., Wang, C., and Wei, W. (2016). Advances in plant-based inhibitors of P-glycoprotein. J. Enzyme Inhib. Med. Chem. 31 (6), 867-881. doi:10.3109/14756366.2016.1149476

Zander, S. A. L., Kersbergen, A., Van der Burg, E., de Water, N., van Tellingen, O., Gunnarsdottir, S., et al. (2010). Sensitivity and acquired resistance of BRCA1; p53-deficient mouse mammary tumors to the topoisomerase I inhibitor topotecan. Cancer Res. 70 (4), 1700-1710. doi:10.1158/0008-5472.Can-09-3367

Zhan, M., Zhao, X., Wang, H., Chen, W., Xu, S., Wang, W., et al. (2016). miR-145 sensitizes gallbladder cancer to cisplatin by regulating multidrug resistance associated protein 1. Tumor Biol. 37 (8), 10553-10562. doi:10.1007/s13277-016-4957-6

Zhang, G.-N., Zhang, Y.-K., Wang, Y.-J., Gupta, P., Ashby, C. R., Jr., Alqahtani, S., et al. (2018). Epidermal growth factor receptor (EGFR) inhibitor PD153035 reverses ABCG2-mediated multidrug resistance in non-small cell lung cancer: in vitro and in vivo. Cancer Lett. 424, 19-29. doi:10.1016/j.canlet.2018.02.040

Zhang, H., Patel, A., Ma, S.-L., Li, X. J., Zhang, Y.-K., Yang, P.-Q., et al. (2014). In vitro, in vivoandex vivocharacterization of ibrutinib: a potent inhibitor of the efflux function of the transporter MRP1. Br. J. Pharmacol. 171 (24), 5845-5857. doi:10.1111/bph.12889

Zhang, L., Mao, Y., Gao, Z., Chen, X., Li, X., Liu, Y., et al. (2020). The nonclinical pharmacokinetics and prediction of human pharmacokinetics of SPH3127, a novel direct renin inhibitor. Eur. J. Drug Metab. Pharmacokinet. 45 (1), 15-26. doi:10.1007/s13318-019-00573-9

Zhang, W., St Clair, D., Butterfield, A., and Vore, M. (2016). Loss of Mrp1 potentiates doxorubicin-induced cytotoxicity in neonatal mouse cardiomyocytes and cardiac fibroblasts. Toxicol. Sci. 151 (1), 44-56. doi:10. 1093/toxsci/kfw021

Zhang, Y., Guo, L., Huang, J., Sun, Y., He, F., Zloh, M., et al. (2019). Inhibitory effect of berberine on broiler P-glycoprotein expression and function: in situ and in vitro studies. Int. J. Mol. Sci. 20 (8), 1966. doi:10.3390/ijms20081966

Zhou, S. F., Wang, L. L., Di, Y., Xue, C., Duan, W., Li, C., et al. (2008). Substrates and inhibitors of human multidrug resistance associated proteins and the implications in drug development. Curr. Med. Chem. 15 (20), 1981-2039. doi:10.2174/092986708785132870

Zhou, X. T., Ding, J., Li, H. Y., Zuo, J. L., Ge, S. Y., Jia, H. L., et al. (2020). Hedgehog signalling mediates drug resistance through targeting TAP1 in hepatocellular carcinoma. J. Cell. Mol. Med. 24 (7), 4298-4311. doi:10.1111/jcmm.15090

Zhou, Z.-Y., Wan, L. L., Yang, Q. J., Han, Y. L., Li, D., Lu, J., et al. (2016). Nilotinib reverses $\mathrm{ABCB} 1 / \mathrm{P}$-glycoprotein-mediated multidrug resistance but increases cardiotoxicity of doxorubicin in a MDR xenograft model. Toxicol. Lett. 259, 124-132. doi:10.1016/j.toxlet.2016.07.710

Zu, B., Li, Y., Wang, X., He, D., Huang, Z., and Feng, W. (2014). MDR1gene polymorphisms and imatinib response in chronic myeloid leukemia: a metaanalysis. Pharmacogenomics 15 (5), 667-677. doi:10.2217/pgs.13.222

Conflict of Interest: The authors declare that the research was conducted in the absence of any commercial or financial relationships that could be construed as a potential conflict of interest.

Copyright (c) 2021 Xiao, Zheng, Ma, Tian and Sun. This is an open-access article distributed under the terms of the Creative Commons Attribution License (CC BY). The use, distribution or reproduction in other forums is permitted, provided the original author(s) and the copyright owner(s) are credited and that the original publication in this journal is cited, in accordance with accepted academic practice. No use, distribution or reproduction is permitted which does not comply with these terms. 